\title{
Index des articles parus dans les numéros 1 à 20 de La Bretagne Linguistique
}

\section{CpenEdition}

\section{Journals}

Édition électronique

URL : http://journals.openedition.org/lbl/450

DOI : $10.4000 / \mathrm{lbl} .450$

ISSN : 2727-9383

Éditeur

Université de Bretagne Occidentale - UBO

\section{Édition imprimée}

Date de publication : 1 mars 2016

Pagination : 201-260

ISBN : 979-10-92331-24-0

ISSN : 1270-2412

\section{Référence électronique}

"Index des articles parus dans les numéros 1 à 20 de La Bretagne Linguistique », La Bretagne

Linguistique [En ligne], 20 | 2016, mis en ligne le 01 mai 2020, consulté le 01 octobre 2020. URL : http:// journals.openedition.org//bl/450; DOl : https://doi.org/10.4000/lbl.450

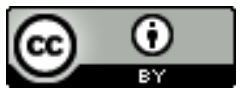

La Bretagne Linguistique est mise à disposition selon les termes de la Licence Creative Commons Attribution 4.0 International. 


\section{Index des articles parus dans les numéros 1 à 20 de La Bretagne linguistique ${ }^{1}$}

\section{Classement par numéro}

\section{La Bretagne linguistique, $\mathrm{n}^{\circ}$ 1, 1985}

LE Dû Jean, « Pourquoi avons-nous créé le GRELB ? », nº 1, 1985, p. 2130.

Le BeRre Yves, «Recherche : problématique et méthodologie », $\mathrm{n}^{\circ} 1$, 1985, p. 31- 37.

Le Berre Annie, "Problèmes d'étude d'un français urbain de BasseBretagne : le parler de Brest », n 1, 1985, p. 39-46.

Plonérs Jean-Marie, «Une autre lecture de l'histoire du monde rural », $\mathrm{n}^{\circ} 1,1985$, p. 47-50.

Tanguy Bernard, "Aspects de la problématique de la dialectologie comparée des domaines roman et breton (Haute et Basse-Bretagne) », $\mathrm{n}^{\circ} 1,1985$, p. 51-58.

FALC'HUN François, « La structure linguistique du domaine bretonnant », $\mathrm{n}^{\circ} 1,1985$, p. $59-71$.

BRoudic François, « La pratique du breton aujourd'hui : approche méthodologique des problèmes d'évaluation », $\mathrm{n}^{\circ} 1,1985, \mathrm{p}$. 73-80.

Follet Jean-Philippe, « Essai de recherche ethnotextuelle à l'Île de Batz (Finistère) $», n^{\circ} 1,1985$, p. 81-83.

FLEURIOT Léon, «Évolutions anciennes et récentes en breton », n 1, 1985, p. 87-97.

GuIOMAR Jean-Yves, « Les historiens et la langue bretonne au XIX ${ }^{\mathrm{e}}$ siècle », $\mathrm{n}^{\circ} 1,1985$, p. $99-102$.

1. Afin d'alléger les références, nous n'indiquons dans cet index que le numéro du volume, l'année de publication et les pages et omettons volontairement le titre de la revue ( $\mathrm{La}$ Bretagne linguistique), la ville et le nom de l'éditeur (Brest, Centre de recherche bretonne et celtique) pour chaque occurrence. 
Plourin Jean-Yves, «L'accentuation en Haute-Cornouaille et en BasVannetais », $\mathrm{n}^{\circ} 1,1985$, p. 103-115.

George Kenneth J., " Le cornique : un cinquième dialecte du breton ? », $\mathrm{n}^{\circ} 1,1985$, p. 117-124.

CADIou Hervé, « Les colloques français-breton à la croisée des rapports du français et du breton », $\mathrm{n}^{\circ} 1,1985$, p. 125-131.

GuYONVARC'H Christian-Joseph, « Dialectes et moyen-breton », $\mathrm{n}^{\circ}$ 1, 1985, p. 133- 135.

Flatrès Pierre, « Lang Kouter (lankouta) - L'argot des tailleurs d'Elliant (Finistère) ", n 1, 1985, p. 137-141.

LE Dû Jean, «Dialectologie et géographie linguistique de la BasseBretagne $», n^{\circ} 1,1985$, p. 145-167.

BENOT Marcel, «Les élèves des cours moyens 1 et 2 de Milizac et la langue bretonne $», n^{\circ} 1,1985$, p. 168-177.

Evenou Yvon, "Oppositions de longueur vocalique et formes canoniques dans le breton de Lanvenegen (canton du Faouët) », n 1, 1985, p. 179189.

Chauveau Jean-Paul, «Quelques emprunts du gallo au breton », $\mathrm{n}^{\circ} 1$, 1985, p. 191-204.

GALLIOU Patrick, "L'Armorique romaine : assimilation ou résistance ? », $\mathrm{n}^{\circ} 1,1985$, p. 205-221.

HewitT Stephen, «Quelques ressemblances structurales entre le breton et l'arabe : conséquence d'une typologie ordinale commune ?», $\mathrm{n}^{\circ} 1$, 1985, p. 223-262.

Le Duc Gwenaël, « La Vie de Geneviève de Brabant : la langue comme écran et révélateur $», \mathrm{n}^{\circ} 1,1985$, p. 263-275.

\section{La Bretagne linguistique, $\mathrm{n}^{\circ} 2,1986$}

Humphreys Humphrey Lloyd, « Projet d'un dictionnaire de la prononciation des toponymes bretons (DPTB) », n² 2, 1986, p. 9-23.

UrIEN Jean-Yves, « Notes sur la démarche typologique : l'ordre des mots, le concept, le sujet, l'indéfini » (commentaires sur la communication de Steve Hewitt présentée à la journée du 11 mai 1985, cf. La Bretagne Linguistique, vol. 1, 1985, p. 223) », $\mathrm{n}^{\circ} 2$, 1986, p. 25-29.

PlonÉIs Jean-Marie, « Toponymie : formes orales et écrites. Évolutions phonétiques », $\mathrm{n}^{\circ}$ 2, 1986, p. 31-35.

FALC'HUN François, «Introduction à une étude des noms de lieux celtiques de la Mayenne, d'après le Dictionnaire topographique du département par Léon Maître (1878)», n² 2, 1986, p. 37-39. 
PILCH Herbert, «L'accentuation de la langue bretonne », $\mathrm{n}^{\circ} 2$, 1986, p. 4368.

Le Berre Annie, « Réflexions sur la section "sociolinguistique et ethnolinguistique" du bulletin signalétique du CNRS (sciences du langage) : reflets d'un partage du monde ", $\mathrm{n}^{\circ} 2,1986, \mathrm{p} .70-80$.

Plourin Jean-Yves, CADIC Mireille, «Aspects linguistiques de l'émigration langonnetaise vers l'Amérique », $\mathrm{n}^{\circ} 2,1986$, p. 82-86.

PIRIOU Yann-Ber, « Notes de lecture : Les amours d'un vieillard », $\mathrm{n}^{\circ} 2$, 1986, p. 88-97.

HoRIOT Brigitte, " Le travail de dialectologie dans le domaine de l'ALO », $\mathrm{n}^{\circ} 2,1986$, p. 98-106.

MarCellesi Jean-Baptiste, « La sociolinguistique en France aujourd'hui : les tendances et les équipes $», n^{\circ} 2,1986$, p. 110-122.

Rousseau Jean-Marie, "L'influence des transformations de l'économie bretonne sur la langue bretonne depuis le début du siècle », $\mathrm{n}^{\circ} 2,1986$, p. 126-131.

HewitT Steve, «Le progressif en breton à la lumière du progressif anglais », $\mathrm{n}^{\circ} 2,1986, \mathrm{p} .133-148$.

George Kenneth J., « Un exemple de bilinguisme breton-anglais », $\mathrm{n}^{\circ} 2$, 1986, p. 150-158.

Ropars Jean, «Atlas linguistique des côtes françaises - littoral nord-ouest analyse générale de l'enquête », $\mathrm{n}^{\circ}$ 2, 1986, p. 160-168.

\section{La Bretagne linguistique, $n^{\circ} 3,1987$}

Walter Henriette, « Le gallo hier et aujourd'hui », nº 3, 1987, p. 9-35.

Rousseau Jean-Marie, « La monétarisation de l'économie bretonne. Une approche théorique de la diffusion de la monnaie $», n^{\circ} 3,1987$, p. $37-$ 40.

Hewitt Steve, « Réflexions et propositions sur l'orthographe du breton ", $\mathrm{n}^{\circ} 3,1987$, p. 41-54.

Ropars Jean, «Atlas linguistique des côtes françaises. Île de Sein, conclusions générales de l'enquête ", n 3, 1987, p. 55-63.

Benot Marcel, «Attitudes à l'égard de la langue bretonne », n 3, 1987, p. 65-74.

CAHUZAC Philippe, «Approche théorique et pratique de quelques problèmes posés à la recherche lexicographique d'aujourd'hui », n 3, 1987, p. 77-93.

Flatrès Pierre, «La toponymie orale comme témoignage d'une langue éteinte $», n^{\circ} 3,1987$, p. 95-98. 
LAMBERT Pierre-Yves, « Nouvelles orientations de la recherche dans l'étude des gloses celtiques (en particulier brittoniques) », n 3, 1987, p. 99105 .

Abraham Maryvonne, « Le nom du chien en pays bretonnant », $\mathrm{n}^{\circ}$ 3, 1987, p. 107-116.

CADIOU Hervé, « À propos d'orthographe », n 3, 1987, p. 117-124.

LAURENT Donatien, «La troménie de Locronan. La fête de Lughnasa et le calendrier celtique $», n^{\circ} 3,1987$, p. 127-143.

GoUletQuer Pierre, « Des pierres et des mots ; quelques aspects des convergences entre archéologie et linguistique $», n^{\circ} 3,1987$, p.145-155.

GERMAN Gary, «L'histoire phonologique du déterminant défini et indéfini à Saint-Yvi en Cornouaille selon les observations faites par De Jubainville à Fouesnant en $1874 » n^{\circ} 3$, 1987, p. 157-168.

BUCKLEY Thomas, « La frontière linguistique breton-gallo dans les environs de Plouha », n 3, 1987, p. 169-175.

Deprez Kas, Wynants Armel, «Fouron : insoluble ? », n 3, 1987, p. 177207.

\section{La Bretagne linguistique, $n^{\circ} 4,1989$}

Tristram Hildegard L. C., « Orientation actuelle des études de linguistique historique, et spécialement de philologie celtique, dans les pays de langue allemande $», n^{\circ} 4,1989$, p. 7-32.

GouletQuer Pierre, «Archéologie intégrée - la recherche archéologique et ses facteurs déterminants : l'exemple du Finistère ", n 4, 1989, p. 33-51.

OMNĖs Robert, « Structures et modèles syllabiques », $\mathrm{n}^{\circ}$ 4, 1989, p. 53-78. Galliou Patrick, TANGUY Bernard, "Armorican graffiti - prolégomènes à l'étude des graffites romains d'Armorique », $n^{\circ} 4$, 1989, p. 79-83.

PINOT Jean-Pierre, « Noms donnés par les pêcheurs aux fonds sous-marins sur le plateau continental sud-armoricain $», \mathrm{n}^{\circ} 4$, 1989, p. 85-95.

GARDY Philippe, « Le domaine occitan depuis vingt ans : pratiques linguistiques et revendications, $\mathrm{n}^{\circ} 4,1989$, p. 99-115.

Le Roc'H-Morgère Louis, « Sur Charlemagne et les douze pairs de France, tragédie bretonne du XVII ${ }^{\mathrm{e}}$ siècle $», \mathrm{n}^{\circ} 4,1989, \mathrm{p} .117-119$.

Evenou Yvon, « La proposition dite relative dans le breton de Lanvénégen $», n^{\circ} 4,1989$, p. 121-129.

ROPARS Jean, «Atlas linguistique des côtes françaises. Tentative d'interprétation statistique globale », $\mathrm{n}^{\circ} 4,1989$, p. 131-144. 
ABJEAn René, «Le bilinguisme sur une radio de service public », $\mathrm{n}^{\circ} 4$, 1989, p. 145-151.

CrorX Alain, « Langues du peuple, langues pour le peuple. Les langages des missions bretonnes au dix-septième siècle », $\mathrm{n}^{\circ}$ 4, 1989, p. 155167.

Bourel Claude, «Présentation d'un conte de Haute-Bretagne : Le cheval noir et le vagabond (approche linguistique et symbolique), $\mathrm{n}^{\circ} 4,1989$, p. 169-174.

George Kenneth J., «Quelques réflexions sur l'ordre des mots dans la pièce en moyen breton Buhez Santez Nonn ", n 4, 1989, p. 175-187.

STEPHENS Janig, « La phrase infinitive en breton », $\mathrm{n}^{\circ}$ 4, 1989, p. 189-202. Hewitt Steve, "Un cadre descriptif pour la syntaxe du verbe breton », $n^{\circ} 4,1989$, p. 203-211.

\section{La Bretagne linguistique, $n^{\circ}$ 5, 1991}

SAUZeT Patrick, « La diglossie - conflit ou tabou ? », n 5, 1991, p. 7-40.

GARDY Philippe, " Le personnage du Franchimand comme interlangue ", $\mathrm{n}^{\circ}$ 5, 1991, p. 41-49.

Le GuirRiec Patrick, «La nomenclature des termes de référence en Bretagne $», n^{\circ} 5,1991$, p. 51-56.

Tremblay Hervé, « Remarques sur le parler roman et les noms de lieu du nord-ouest de la Loire-Atlantique », n 5, 1991, p. 57-67.

PlonéIS Jean-Marie, « Le paysan et ses animaux. Quelques aspects linguistiques $», n^{\circ} 5,1991$, p. 69-76.

RAVIER Xavier, " Des choses aux mots, des mots au discours : pour une utilisation maximale des données des atlas linguistiques et ethnographiques », $\mathrm{n}^{\circ}$ 5, 1991, p. 79-97.

MaAs-Chauveau Claudia «Présentation des recherches en onomastique du Patronymia romanica », $\mathrm{n}^{\circ}$ 5, 1991, p. 99-102.

Le RouzIc Suzanne, «Une mutation linguistique en trois étapes », $\mathrm{n}^{\circ} 5$, 1991, p. 103-109.

Brasseur Patrick, «Attitudes linguistiques des Normannophones dans les Iles anglo-normandes $», \mathrm{n}^{\circ}$ 5, 1991, p. 111-127.

RAUDE Alan-J., «La palatalisation des consonnes vélaires en breton et britto-roman », $\mathrm{n}^{\circ}$ 5, 1991, p. 129-136.

Lambert Pierre-Yves, « La situation linguistique de la Bretagne au Haut Moyen Âge », n 5, 1991, p. 139-151.

Ropars Jean, «L'enfant et l'école : une expérience caractéristique. Étude d'analyse ethnotextuelle », $\mathrm{n}^{\circ}$ 5, 1991, p. 153-177. 
URIEN Jean-Yves, «Le syntagme «existentiel» en breton. Définition syntaxique et sémantique $(\mathrm{X}+\mathrm{zo} / \mathrm{n}$ 'eus ket $+\mathrm{X}$, “Il y a X / il n'y a pas X")», n 5, 1991, p. 179-194.

Le BERRE Annie, «Bretagne : terre incognita? À propos d'une enquête sur la connaissance de la Bretagne dans une classe de première brestoise, année scolaire 1987-1988 », n 5, 1991, p. 197-218.

\section{La Bretagne linguistique, $n^{\circ}$ 6, 1992}

PlÖTNER Bärbel, « La correspondance entre Hersart de La Villemarqué et un savant allemand, Jacob Grimm », n 6, 1992, p. 7-44.

Banks David, "Transitivité systémique et analyse du texte », $\mathrm{n}^{\circ}$ 6, 1992, p. 45-52.

Flatrès Pierre, «Anglo-Saxons, Anglo-Normands, Anglo-Français, Anglo-Celtiques », ${ }^{\circ} 6,1992$, p. 53-65.

BALCOU Jean, «Ernest Renan et la langue bretonne », n 6, 1992, p. 69-78. SIMON Jean-François, " Recettes médicinales sur un cahier d'écolier du XVIII ${ }^{\mathrm{e}}$ siècle $», \mathrm{n}^{\circ} 6,1992$, p. 79-90.

RHIour Ahmed, "Un écart balbutiant une quête de statut », $n^{\circ}$ 6, 1992, p. $93-102$.

Broudic Fañch, «L'usage abusif du breton en 1902 : le point de vue du clergé », nº 6, 1992, p. 103-142.

Le Duc Gwenaël, "La lettre d'un recteur de Muzillac à sa servante (1793) », nº 6, 1992, p. 143-158.

Le Berre Yves, "Un 'Supplément' au Livr el labourer de Joachim Guillôme », n 6, 1992, p. 159-174.

PILCH Herbert, «L'intonation de la langue bretonne », $\mathrm{n}^{\circ}$ 6, 1992, p. 175182.

STump Gregory T., « La morphologie bretonne et la frontière entre la flexion et la dérivation $», \mathrm{n}^{\circ} 6,1992$, p. 185-237.

Guyonvarc' H Christian-Joseph, "La langue gauloise dans le De Bello gallico $», n^{\circ} 6,1992$, p. 239-251.

GouletQuer Pierre, «Opacité sémantique et discontinuité de l'information archéologique », $n^{\circ} 6,1992$, p. 253-254.

BÉCHEREL Danielle, «Restrictions sémantiques dans la transformation adjectif/substantif », $n^{\circ} 6,1992$, p. 255-261.

RAUDE Alan-J., " La signalisation bilingue des noms de communes en Bretagne bretonnante $», n^{\circ}$ 6, 1992, p. 263-276. 


\section{La Bretagne linguistique, $\mathrm{n}^{\circ}$ 7, 1993}

KRIER Fernande, «Le trilinguisme au Luxembourg », n 7, 1993, p. 7-20.

LE Dû Jean, « Pour un Atlas linguistique collectif de la langue bretonne », $\mathrm{n}^{\circ}$ 7, 1993, p. 21- 30.

FAVEREAU Francis, «Quatre générations de bretonnants », nº 7, 1993, p. 3152.

Flatrès Pierre, "Abandon de langue et transmission de traditions : à propos de quelques rencontres avec le paganisme celtique $», \mathrm{n}^{\circ} 7$, 1993, p. 53-58.

SAULNIER Claude, « La situation sociolinguistique à Carhaix au début du siècle », $\mathrm{n}^{\circ}$ 7, 1993, p. 59-75.

NiLSEN Kenneth E., « Le gaélique en Nouvelle-Écosse », n 7, 1993, p. 7991.

NoAilly Michèle, «Autour du défini cataphorique », n 7, 1993, p. 93-102.

Gouletquer Pierre, "Barnenez-ar-Zant et ses symboles », n 7, 1993, p. 103-133.

Raude Alan-J., « La fonction énonciative », n 7, 1993, p. 135-140.

LE BESCo Patrick, « Le breton de Belle-Île-en-Mer, quelques caractéristiques », n 7, 1993, p. 141-149.

Le BerRe Yves, « L'écriture du breton dans l'histoire. Essai de synthèse », $\mathrm{n}^{\circ}$ 7, 1993, p. 153-176.

GERMAN Gary, «Une méthode dialectométrique (assistée par ordinateur) pour l'analyse des atlas linguistiques », $\mathrm{n}^{\circ}$ 7, 1993, p. 177-213.

BRoudic Fañch, " Réalisation d'une enquête sur la pratique du breton », $n^{\circ} 7,1993$, p. 215-222.

CAdiou Hervé, «Y a-t-il eu une influence de la langue écrite sur le parler du Léon ?», n 7, 1993, p. 223-226.

LeCOCQ Jean-Marc, « Les mots d'origine bretonne dans l'argot français », $\mathrm{n}^{\circ} 7,1993$, p. 227-238.

\section{La Bretagne linguistique, $n^{\circ}$ 8, 1994}

Guiomar Jean-Yves, «L'introduction en France des idées sur l'origine celtique de la littérature française par l'Abbé Gervais de La Rue », $\mathrm{n}^{\circ}$ 8, 1994, p. 7-89.

Plonérs Jean-Marie, «Toponymie : contribution à la dialectologie bretonne $», n^{\circ} 8,1994$, p. 91-97.

HumphreYs Humphrey Lloyd, «Présentation des hebdomadaires de langue galloise $», n^{\circ} 8,1994$, p. 99-104. 
Le BesCo Patrick, «L'argot des maçons de la Forêt-Fouesnant », $\mathrm{n}^{\circ} 8$, 1994, p. 105-106.

Le Rouzic Suzanne, «Un écrivain de langue bretonne l'Abbé Pierre Noury : $1743-1804 », n^{\circ} 8,1994$, p. 107-111.

BALIBAR Renée, «Langues internationales et minorités linguistiques », $\mathrm{n}^{\circ} 8,1994$, p. 115-122.

LAMPLE Bernard, " Les pêcheurs kerhorres : une communauté originale dans la rade de Brest $», n^{\circ} 8,1994$, p. 123-134.

KALYGUINE Victor, "La poétique irlandaise archaïque du point de vue mythologique. Domestication de l'espace », n 8, 1994, p. 135-143.

Evenou Yvon, "Breton et culture bretonne dans l'éducation nationale », $\mathrm{n}^{\circ}$ 8, 1994, p. 145-154.

LECOCQ Jean-Marc, « Les argots bretons, langages secrets professionnels en Basse-Bretagne », $\mathrm{n}^{\circ}$ 8, 1994, p. 155- 162.

Goebl Hans, «Trois coups d'œil rapides sur la situation sociolinguistique dans les Alpes centrales - Grisons, Tyrol du Sud / Haut-Adige, Carinthie méridionale », $\mathrm{n}^{\circ}$ 8, 1994, p. 165-193.

Flatrès Pierre, « La notion de nation dans les Iles Britanniques », $\mathrm{n}^{\circ} 8$, 1994, p. 195-207.

ELoy Jean-Michel, « La langue est de nature sociale », n 8, 1994, p. 209222.

Hughes Arthur John, « Les mots qui désignent le cheval dans les langues gaéliques du point de vue de la géographie linguistique », $\mathrm{n}^{\circ} 8,1994$, p. 223-259.

Bernier Gildas, «Phonologie du breton de Quiberon », n 8, 1994, p. 261271.

\section{La Bretagne linguistique, $n^{\circ}$ 9, 1997}

BERNABÉ Jean, «Un regard nouveau sur la diglossie français-créole. Esquisse d'une approche écosystémique des langues », $\mathrm{n}^{\circ}$ 9, 1997, p. 7-18.

Chauveau Jean-Paul, « Le Französisches Etymologisches Wörterbuch de Walter von Wartburg et son intérêt pour des celtisants », $\mathrm{n}^{\circ}$ 9, 1997, p. 19-37.

Chetounan Lamria, « Lexicométrie et débats politiques sur l'environnement $», n^{\circ}$ 9, 1997, p. 39-64.

Goyat Gilles, « Prosodie et prosodie musicale », n 9, 1997, p. 65-76.

Humphreys Humphrey Lloyd, «Présentation des hebdomadaires de langue galloise $», \mathrm{n}^{\circ}$ 9, 1997, p. 77-81. 
IsAAC Luc, «Aspects de la question linguistique en Belgique », $\mathrm{n}^{\circ}$ 9, 1997, p. 83-98.

Le Berre Yves, Le Dû Jean, "L'élaboration d'une banque de données textuelles du breton », $n^{\circ}$ 9, 1997, p. 99-104.

Manzano Francis, «Identité et frontière : linéaments d'une recherche sur le contact normano-breton $», n^{\circ}$ 9, 1997, p. 105-125.

Plourin Jean-Yves, «De quelques mots bretons anciens », $\mathrm{n}^{\circ}$ 9, 1997, p. 127-135.

Ropars Jean, «Contribution à l'histoire des mentalités : une méthode de recherche $», n^{\circ} 9,1997$, p. 137-151.

\section{La Bretagne linguistique, $\mathrm{n}^{\circ}$ 10, 1996}

Actes du colloque « Badume - Standard - Norme. Le Double Jeu de la langue»

Le Dû Jean et Le Berre Yves, « Parité et disparité. Sphère publique et sphère privée de la parole », $\mathrm{n}^{\circ}$ 10, 1996, p. 7-25.

BALIBAR Renée, "Colinguisme et dissonances. Les enjeux du travail des langues », $\mathrm{n}^{\circ} 10,1996, \mathrm{p} .27-32$.

Eloy Jean-Michel, «La République et les registres langagiers ", $\mathrm{n}^{\circ} 10$, 1996, p. 33-56.

WynANTS Bernadette, «Transformations du rapport à la norme », $\mathrm{n}^{\circ} 10$, 1996, p. 57-67.

BRouDIC Fañch, «Langues parlées, langues écrites en Basse-Bretagne, 1946-1990», n 10, 1996, p. 69-79.

HumPHREYs Humphrey Lloyd, «Réflexions sur les localismes et le supralocalisme en anglais, en gallois et en breton $», \mathrm{n}^{\circ}$ 10, 1996, p. 81-95.

NiLSEN Ken, « Le gaélique en Nouvelle-Écosse : survivance d'une langue orale au Nouveau Monde », n 10, 1996, p. 97-103.

Caitucoli Claude, Sanogo Mamado L., Tsekos Nicolas, «Le PasseMuraille. Réalités langagières au Burkina Faso et en Grèce », $\mathrm{n}^{\circ}$ 10, 1996, p. 105-122.

FAVEREAU Francis, « Normalisation d'un conte breton : à la recherche de l'impossible norme », $\mathrm{n}^{\circ} 10,1996$, p. 123-131.

LAROUSSI Foued, «Frontières linguistiques et pratiques langagières : Le cas tunisien », n 10, 1996, p. 133-142.

AkIN Salih, "Représentations idéologiques et réalités langagières : le cas du kurde », n 10, 1996, p. 143-151.

Clairis Christos, « La réforme linguistique en Turquie », $\mathrm{n}^{\circ}$ 10, 1996, p. $153-157$. 
JONES Mari, «Le parler des jeunes : nouvelle norme pour le siècle prochain? », n 10, 1996, p. 159-168.

TABOuret-Keller Andrée, « Le nom des langues », n 10, 1996, p. 169176.

Tristram Hildegard L. C., Hemprich Gisbert, « Esquisse de la situation linguistique actuelle de Fribourg-en-Brisgau (Allemagne) », $\mathrm{n}^{\circ} 10$, 1996, p. 177-188.

Deprez Kas, « Soldats du Néerlandais », n 10, 1996, p. 189-215.

WynANTs Armel, « Les fourons : Platt-Dütsch, Wallon, Néerlandais, Allemand, Français », n 10, 1996, p. 217-229.

KRIER Fernande, «La diversité dans l'unité : les langues minoritaires », $\mathrm{n}^{\circ} 10,1996$, p. $231-237$.

HouDEBINE Anne-Marie, «Imaginaire linguistique et dynamique langagière. Aspects théoriques et méthodologiques ", $\mathrm{n}^{\circ}$ 10, 1996, p. 239-255.

Hobe-Canut Cécile, «Imaginaire linguistique au Mali», n 10, 1996, p. 257-264.

BRUNET-HunAult Laurence, « Imaginaire linguistique et acquisition de la langue $», \mathrm{n}^{\circ} 10,1996$, p. 265-272.

GALLARD Philippe, «Imaginaire linguistique et français dialectal du Poitou : le sentiment identitaire chez les jeunes », $\mathrm{n}^{\circ} 10,1996$, p. 273-279.

Bothorel-Witz Arlette, Huck Dominique, « La place des dialectes alsaciens dans un modèle variationnel : réflexions sur les notions de variétés et de normes $», n^{\circ} 10,1996$, p. 281-297.

Garcia-Mendez Javier, «Parité et disparité parolières dans le roman hispano-américain », n 10, 1996, p. 299-308.

Cahuzac Philippe, « Badumes, standards, normes. La situation en Amérique hispanique $», \mathrm{n}^{\circ} 10,1996$, p. 309-318.

TOURNIER Maurice, " Discours polémique et schismogenèse linguistique. Le "Naven" du Père Peinard », n 10, 1996, p. 319-328.

GARDY Philippe, " "De l'accordéon (français ?)" Badume, Standard, Norme dans la diglossie franco-occitane ( $\mathrm{XVI}^{\mathrm{e}}-\mathrm{XVIII}{ }^{\mathrm{e}}$ siècles). Imaginaire linguistique et dynamique langagière Aspects théoriques et méthodologiques », $\mathrm{n}^{\circ}$ 10, 1996, p. 329-347.

SAUZET Patrick, "Paradis et parité. Ou : De la coquetterie linguistique », $\mathrm{n}^{\circ} 10,1996$, p. 349-370.

Geffroy Annie, "La lexicométrie: pour une approche mesurée du discours $», \mathrm{n}^{\circ}$ 10, 1996, p. 371-383.

VenY Joan, «Langue historique et langue standard dans le domaine catalan », n 10, 1996, p. 385-394. 


\section{La Bretagne linguistique, $\mathrm{n}^{\circ} 11,1998$}

BALIBAR Renée, «La langue romane-française », $\mathrm{n}^{\circ}$ 11, 1998, p. 7-15.

Blanchet Philippe, "Regard sur la dynamique ethno-sociolinguistique actuelle de la Provence, ou quand l'identité fait reculer la diglossie », $\mathrm{n}^{\circ} 11,1998$, p. $17-31$.

Brun-Trigaud Guylaine, «À propos des atlas linguistiques régionaux. Problèmes de comparabilité », $\mathrm{n}^{\circ} 11,1998$, p. 33-49.

BRoudic Fañch, « La recherche sur la pratique du breton : objet, méthodes et perspectives », $n^{\circ} 11,1998$, p. 51-75.

CAlvez Ronan, « Vie et mort du paysanisme breton : Feiz ha Breiz (18651875) », n 11, 1998, p. 77-96.

Calvez Ronan, " "Les Bretons parlent aux Bretons". Radio-Quimerc'h : les débuts de la radio en breton », $\mathrm{n}^{\circ} 11,1998$, p. 97-113.

Costaouec Denis, « Sociolinguistique et étude des changements linguistiques en synchronie $», \mathrm{n}^{\circ} 11,1998, \mathrm{p} .115-119$.

DAlbera Jean-Philippe, «Espace et variation linguistique : description et modélisation. Les bases de données THESOC et ALCANOM », $\mathrm{n}^{\circ} 11$, 1998, p. 121-134.

Dalbera-Stefanaggi Marie-José, «La base de données dialectales : un instrument de sauvegarde et de recherche. L'exemple corse », $\mathrm{n}^{\circ} 11$, 1998, p. 135-152.

Eloy Jean-Michel, «Dans quel sens peut-on dire que le picard est une langue minoritaire ? », $\mathrm{n}^{\circ} 11,1998, \mathrm{p} .153-168$.

FaLL Khadiyatoulah, "Le jeu des identités ou la plasticité du lexème "intégration" ", n 11, 1998, p. 169-177.

FAUQUET Eric, « La question de la génialité de la langue. Transfert des idées de Herder en France », n 11, 1998, p. 179-186.

GACHELIN Jean-Marc, «Le purisme en général, et anglo-saxon en particulier $», \mathrm{n}^{\circ} 11,1998$, p. 187-202.

GERMAN Gary, «Langue et identité : une enquête sociolinguistique menée dans huit écoles galloises portant sur les attitudes envers le gallois et l'anglais », $\mathrm{n}^{\circ} 11,1998$, p. 203-205.

Gouletquer Pierre, «Cadastre napoléonien, archéologie et territoires parlés », $\mathrm{n}^{\circ} 11,1998$, p. 207-212.

GouletQuer Pierre, "Géographie linguistique et archéo-géographie; plaidoyer pour des démarches interdisciplinaires », $\mathrm{n}^{\circ} 11,1998$, p. 213-225.

Guillou Anne, « Les femmes et le breton », n 11, 1998, p. 227-231. 
Le Dû Jean et Le Berre Yves, « Faits de langues, faits de sociétés », nº 11, 1998, p. 233-243.

Le Monze Sylvie, «Tutoiement, vouvoiement et autres formes d'adresse en français de Bretagne », $\mathrm{n}^{\circ}$ 11, 1998, p. 245-251.

L'HourRe Ronan, « Le changement de langue (en Basse Bretagne) : pour une approche centrée sur le sujet parlant », $\mathrm{n}^{\circ} 11,1998$, p. 253-271.

Megdiche Cyrille, «Approche sociologique des relations interethniques en milieu urbain », $\mathrm{n}^{\circ} 11,1998$, p. 273-281.

PLouRIN Jean-Yves, « La phrase bretonne comprenant le verbe ÊTRE au présent de l'indicatif. Conflits de topicalisation », n 11, 1998, p. 283300 .

\section{La Bretagne linguistique, $\mathrm{n}^{\circ} 12,1998$}

\section{Actes du colloque « $\mathrm{Y}$ a-t-il une exception sociolinguistique française ? »}

Le Dû Jean, Le Berre, Yves, «Y a-t-il une exception sociolinguistique française ? ", $n^{\circ} 12,1998$, p. 11-26.

LAFONT Robert «Langues en contact / langues en conflit ; trente ans de sociolinguistique périphérique : cinq concepts revisités $», \mathrm{n}^{\circ} 12,1998$, p. 27-38.

MarCellesi Jean-Baptiste, " Contribution à l'histoire de la sociolinguistique : origines et développement de l'école rouennaise », $\mathrm{n}^{\circ} 12,1998$, p. 39-57.

LODGE Anthony, «En quoi pourrait consister l'exception sociolinguistique française ? », $\mathrm{n}^{\circ} 12,1998$, p. 59-74.

BRUN-TRIGAUd Guylaine, " La limite oc-oïl : un débat franco-allemand », $\mathrm{n}^{\circ} 12,1998$, p. $75-82$.

WyNANTS Bernadette, «Usages et représentations de l'orthographe française $», \mathrm{n}^{\circ} 12,1998$, p. 83-88.

TABouret-KelLER Andrée, "Les "langues dialectales ou encore locales" sous le régime de Vichy », n 12, 1998, p. 89-116.

Eloy Jean-Michel, « La fille aînée du latin... est restée célibataire trop longtemps », $\mathrm{n}^{\circ} 12,1998$, p. 117-140.

LÉONARD Jean Léo, « Diasystème et diglossie périphérique : le "cas galloroman" », $\mathrm{n}^{\circ} 12,1998$, p. 141-174.

GARDY Philippe, «Une étrange aversion? Jean Giono écrivain, "analyseur” de la situation sociolinguistique française ? », $\mathrm{n}^{\circ} 12,1998$, p. 175-194.

Martel Philippe, "L'image de l'occitan dans l'opinion au XIX siècle ", $\mathrm{n}^{\circ} 12,1998$, p. 195-217.

BRoudic Fañch, « La faute à l'abbé Grégoire ? », n 12, 1998, p. 219-228. 
Meraoui Frédéric, "De la difficulté d'être soi-même entre France et Allemagne, entre modernité et tradition », n 12, 1998, p. 229-241.

Keryell Gaela, "La communauté des locuteurs citoyens et la communauté des locuteurs parents, nationalisme "politique" et nationalisme "culturel" ", n 12, 1998, p. 243-275.

AHLQvist Anders, « La situation sociolinguistique de l'irlandais », $\mathrm{n}^{\circ} 12$, 1998, p. 277-286.

Deprez Kas, « Pourquoi la langue officielle de la Flandre n'est-elle pas le flamand, mais le néerlandais ? », $\mathrm{n}^{\circ} 12,1998$, p. 287-322.

WynANTs Armel, «La Belgique francophone, la Wallonie et le français ", $n^{\circ} 12,1998$, p. 323-335.

Veсcнiо Sebastiano, «Y a-t-il une exception sociolinguistique italienne ? Le cas de la Sicile », $n^{\circ} 12,1998$, p. 337-247.

\section{La Bretagne linguistique, $\mathrm{n}^{\circ}$ 13, 2004 « Dialectologie et Géolinguistique »}

LE Dû Jean, « Introduction : La dialectologie et la géolinguistique bougent encore! », $n^{\circ} 13,2004$, p. 5-11.

BlanCHARD Nelly, "L'utilisation pédagogique des textes du concours $\mathrm{Ar}$ Falz », n० 13, 2004, p. 13-29.

BRoudic Fañch, «La perception de la variation diatopique au fil du temps », $\mathrm{n}^{\circ} 13,2004$, p. 31-52.

BRUN-Trigaud Guylaine, « Le breton : un éclairage sur l'histoire des parlers gallo-romans? », $\mathrm{n}^{\circ} 13,2004$, p. 53-71.

FAGON Christian, « Changement du/z/ en /h/ en Léon : continuité du brittonique au breton moderne et regard sociolinguistique des locuteurs sur ce phénomène $», \mathrm{n}^{\circ} 13,2004$, p. 73-83.

FAVEREAU Francis, « Déictiques spatio-temporels en breton central », $\mathrm{n}^{\circ} 13$, 2004, p. 85-103.

Giraudon Daniel, «Ornithonymes et breton populaire. Des cris, des couleurs, des mœurs et des genres $», n^{\circ} 13,2004$, p. 105-127.

Goyat Gilles, « La deuxième personne dans le parler breton de Plozévet », $\mathrm{n}^{\circ} 13,2004$, p. 129-138.

LEDUNOIS Jean-Pierre, « Grammaire et dialectologie », n 13, 2004, p. 139156.

Le PiPec Erwan, «Lecture critique du Nouvel Atlas Linguistique de la Basse-Bretagne $», \mathrm{n}^{\circ} 13,2004$, p. 157-175.

Plourin Jean-Yves, " La grammaire bretonne à l'épreuve des dialectes ", $\mathrm{n}^{\circ} 13,2004$, p. 177-193. 
QUÉRÉ Anne-Marie, « Une conversation en breton de Plaudren », $\mathrm{n}^{\circ}$ 13, 2004, p. 195-209.

Riou Yann, « À propos du breton de Lampaul-Plouarzel », $n^{\circ}$ 13, 2004, p. 211-226.

Rolland Pascal, "Deux prônes en "breton de Vannes" de la première moitié du XVIII" siècle », $\mathrm{n}^{\circ}$ 13, 2004, p. 227-252.

UrIEN Jean-Yves, « Les Mots en “DIA-", la langue et la socialité », $\mathrm{n}^{\circ} 13$, 2004, p. 253-279.

CAnobbio Sabina, "L'Atlas Linguistique comme outil de recherche ? À propos de quelques expériences italiennes ", $\mathrm{n}^{\circ} 13,2004$, p. 281-312.

GACHELIN Jean-Marc, « Un aperçu du lexique de l'anglais dialectal », $\mathrm{n}^{\circ} 13$, 2004, p. 313-330.

García-Mouton Pilar, "Sur la dialectologie espagnole », $\mathrm{n}^{\circ}$ 13, 2004, p. 331-340.

GERMAN Gary, «Analyse diachronique et variationniste de la désinence du pluriel -EN en anglais standard et non standard », $n^{\circ} 13,2004$, p. 105127.

Goebl Hans, « Brève présentation de l'Atlas linguistique ladin (ALD 1ère et $2^{\mathrm{e}}$ partie) $», \mathrm{n}^{\circ} 13,2004$, p. 375-381.

Kretzschmar William A., «Vingt années de l'American Linguistic Atlas Project $», n^{\circ} 13,2004$, p. 383-400.

\section{La Bretagne linguistique, $n^{\circ}$ 14, 2009}

Yves Le Berre, « À propos du Stabat Mater breton de Tanguy Guéguen (1622) : le "moyen-breton" existe-t-il ? », n 14, 2009, p. 13-24.

CALvez Ronan, « La métaphore mondaine. Kerenveyer et les littératures du breton $», \mathrm{n}^{\circ} 14,2009$, p. 25-40.

Thomas Mannaig, " "Le paysage de la grève de Penhors" : un tableau extrait du Cheval d'orgueil de Pierre-Jakez Hélias », n 14, 2009, p. 41-56.

Le PIPEC Erwan, « La phrase négative en breton : de la phonologie à la syntaxe $», n^{\circ} 14,2009$, p. 57-67.

Le Dû Jean, «Thésaurus des noms de poissons d'animaux marins et du bord de mer des côtes de Basse-Bretagne », $\mathrm{n}^{\circ}$ 14, 2009, p. 69-79.

Guillorel Éva, «Le Barzaz Bro-Leon, ou la tentative d'un nouveau Barzaz-Breiz : premières approches d'un fonds inédit de près de 1000 chansons en breton $», n^{\circ} 14,2009$, p. 81-92.

Blanchard Nelly, «Le manuscrit autobiographique d'Hervé Burel : le peuple dit par lui-même? " n ${ }^{\circ}$ 14, 2009, p. 93-105. 
Mouton Jacques-Yves, «Le mythe de Tir Na N-og chez les premiers Liammistes $», \mathrm{n}^{\circ} 14,2009$, p. 107-113.

JouitTEAu Mélanie, Rezac Milan, « Le verbe "avoir” à travers les dialectes du breton $», n^{\circ} 14,2009$, p. 115-141.

Plourin Jean-Yves, "Continu et discontinu dans le groupe nominal», $\mathrm{n}^{\circ} 14,2009$, p. 143-174.

Le Bris Daniel, « Les études linguistiques d'Edward Lhuyd en Bretagne en $1701 », n^{\circ} 14,2009$, p. 175-193.

BARRÉ Ronan, "Langue et économie : quelques pistes de recherche », $\mathrm{n}^{\circ} 14,2009$, p. 195-206.

JoRGENSEN Anders Richardt, "On Breton "meliner" (miller) and other agent noun derivatives with Latin "ator" ", $\mathrm{n}^{\circ} 14,2009$, p. 207-226.

FAVEREAU Francis, «Le je(u) de chaises musicales du breton », n 14, 2009 , p. 227-239.

\section{La Bretagne linguistique, $n^{\circ}$ 15, 2010}

Audic Armelle, «La langue bretonne à Arradon au $\mathrm{Xx}^{\mathrm{e}}$ siècle. Essai de recherche ethno-socio-linguistique illustré par un exemple : C'hoari an Tri Roue hag ar Bassion », $\mathrm{n}^{\circ}$ 15, 2010, p. 7-27.

Cheveau Loic, « Le breton de Ploemeur d'après l'ALBB de P. Le Roux : lecture critique $», n^{\circ} 15,2010$, p. 29-42.

IRSLINGER Britta, «Les dérivés gallois, cornique en - $y n /-e n$, breton en -enn et irlandais en -ne : fonction et sémantique », $\mathrm{n}^{\circ} 15,2010$, p. 43-81.

German Gary, " "Badume, Standard et Norme" à la lumière de l'anglais vernaculaire des Appalaches ", n 15, 2010, p. 83-107.

BRoudic Jean-Yves, «Changement linguistique et processus psychiques inconscients liés à un trauma collectif : le cas de la Basse-Bretagne ", $\mathrm{n}^{\circ} 15,2010$, p. 109-116.

Le Rol Jean-Paul, «La Passion de Pleudaniel : étude linguistique et sociolinguistique $», \mathrm{n}^{\circ} 15,2010$, p. 117-122.

Costaouec Denis, «Contraintes et libertés en phonologie : neutralisations et faits d'assimilation en breton $», \mathrm{n}^{\circ} 15,2010$, p. 123-145.

FolLEt Jean-Philippe, « Île de Batz : le paysage sociolinguistique au début des années $1980 », \mathrm{n}^{\circ} 15,2010$, p. 146-159.

Giraudon Daniel, «Les blasons populaires en Bretagne », $\mathrm{n}^{\circ}$ 15, 2010, p. 161-168.

Postic Fañch, «Le fonds La Villemarqué : une source importante pour l'histoire de l'ethnographie et des études celtiques », $\mathrm{n}^{\circ} 15,2010$, p. 169-183. 
BROUDIC Fañch, « Les nouveaux sondages sur la pratique du breton et celle de l'occitan en Aquitaine », $\mathrm{n}^{\circ}$ 15, 2010, p. 185-193.

CASSARD Jean-Christophe, "Le breton dans la bd franco-belge », $\mathrm{n}^{\circ} 15$, 2010, p. 195-223.

HellegouarC'H Anne, «Cymuned - aux grands maux les grands remèdes », $\mathrm{n}^{\circ} 15,2010$, p. 225-247.

KeRSULEC Pierre-Yves, «Les noms en -erezh à référence collective : esquisse de classement $», \mathrm{n}^{\circ} 15,2010$, p. 249-274.

\section{La Bretagne linguistique, $\mathrm{n}^{\circ}$ 16, 2011}

Vıolo Gaëlle, «Ethnographie des transmissions familiales de la langue bretonne en Basse-Bretagne », $\mathrm{n}^{\circ}$ 16, 2011, p. 7-18.

Choplin Cédric, «Feiz ha Breiz (1865-1884) ou la genèse d'une langue journalistique $», \mathrm{n}^{\circ} 16,2011$, p. 19-35.

Bougthon Zoë, « La standardisation continue de la langue française : 1'apport des perceptions et attitudes langagières $", n^{\circ} 16,2011$, p. 37-57.

LE Dû Jean, «Un atlas linguistique du créole des Petites Antilles (ALPA)» $\mathrm{n}^{\circ} 16,2011$, p. 59-74.

RoBerTs Richard Glyn, « La Critique textuelle en rupture avec la grille épistémologique : esquisse d'une analyse des recueils de proverbes gallois du Moyen Âge », n 16, 2011, p. 75-85.

Goyat Gilles, « La langue bretonne dans la Mission de folklore musical de Basse-Bretagne de $1939 », n^{\circ} 16,2011$, p. 87-96.

LE RuYET Jean-Claude, « Effet Buben, liaison et modèles orthographiques bretons $», \mathrm{n}^{\circ} 16,2011$, p. 97-109.

QuéRÉ Anne-Marie, "Remarques sur le breton parlé à Plaudren » $\mathrm{n}^{\circ} 16$, 2011, p. 111-122.

Le Berre Yves, « La force et l'élégance. Les litotes dans la Passion bretonne de $1530 », \mathrm{n}^{\circ} 16,2011$, p. 123-149.

CARney Sébastien, « Célestin Lainé et le breton : la langue pour le combat », $\mathrm{n}^{\circ} 16,2011$, p. 151-197.

\section{La Bretagne linguistique, $\mathrm{n}^{\circ}$ 17, 2013}

CoËtanlem Pierre-Joseph-Jean, «Préface », n 17, 2013, p. 7-14.

Calvez Ronan, « Les mots et les causes. Du Dictionnaire de Coëtanlem », $n^{\circ} 17,2013$, p. 15-24.

Postic Fañch, «Les dictionnaires bretons, une source pour l'ethnographie : l'article "Eghinat" chez Coëtanlem et Le Pelletier », $\mathrm{n}^{\circ} 17$, 2013, p. 25-64. 
Simon Jean-François, «Pour une meilleure connaissance des techniques agricoles anciennes de Bretagne. La lexicographie au service de la technologie $», n^{\circ} 17,2013$, p. 65-79.

Calvez Ronan, «Les mots et les sources », n 17, 2013, p. 81-109.

LE Bris Daniel, «Entre Penzé et Rivière de Morlaix : termes nautiques bretons relevés par Coëtanlem », n 17, 2013, p. 111-123.

Le Berre Yves, «Présentation de la journée du 11 février 2011 », $\mathrm{n}^{\circ}$ 17, 2013, p. 125-126.

CAlvez Ronan, « Amours cachées : la nouvelle rhétorique mondaine bretonne $», n^{\circ} 17,2013$, p. 127-139.

Le BerRe Yves, « Rhétorique des gwerziou », $\mathrm{n}^{\circ}$ 17, 2013, p. 141-160.

BlanCHARD Nelly, « Les doublets synonymiques chez Hervé Burel (1905) ou comment casser l'entre-soi », $\mathrm{n}^{\circ} 17,2013$, p. 161-180.

Thomas Mannaig, "La rhétorique "Kleiz Breizh" ", n 17, 2013, p. 181201.

JøRGENSEN Anders Richardt, « On the sources and transmission of the Early Vannetais noels $», \mathrm{n}^{\circ} 17,2013$, p. 203-231.

LysAGHT Ruth, «L'image des langues minoritaires à travers les médias contemporains $», \mathrm{n}^{\circ} 17,2013$, p. 233-252.

Dell'Aquila Vittorio, IANNACCARo Gabriele, «Quelques considérations sur la cartographie des données linguistiques », $\mathrm{n}^{\circ} 17,2013$, p. 253-286.

\section{La Bretagne linguistique, $\mathrm{n}^{\circ}$ 18, 2014}

Blanchard Nelly, «Julien Godest, paysan autobiographe sous l'aile de Taldir-Jaffrennou », $\mathrm{n}^{\circ} 18,2014$, p. 7-31.

ADAM Catherine, «Élaboration d'une recherche en sociolinguistique sur les représentations parentales et leurs influences : le cas du bilinguisme scolaire breton-français du jeune enfant $», n^{\circ} 18,2014$, p. 33-55.

Brun-Trigaud Guylaine, "Le Thesaurus Occitan, une base de données multimédiale dédiée aux dialectes occitans », n 18, 2014, p. 57-72.

Le Bris Daniel, Carpitelli Elisabetta, « Concordances linguistiques entre aires celtique et romane à partir des données des atlas multilingues ", $\mathrm{n}^{\circ} 18,2014$, p. $73-85$.

Desseigne Adrien, Kersulec Pierre-Yves, « Les enquêtes dialectologiques de la Société d'Ethnolinguistique Bretonne : éléments de présentation du Questionnaire grammatical $1500 », n^{\circ} 18,2014$, p. 87-109.

LE GALL Laurent, « La Bretagne, une illusio qui fonctionne », $\mathrm{n}^{\circ}$ 18, 2014, p. 11-136.

Le PIPEC Erwan, « Le breton, langue-totem? », n 18, 2014, p. 137-176. 
Thomas Mannaig, "Une littérature en dépendances. La littérature de langue bretonne 2000-2010», n 18, 2014, p. 177-203.

LouIs François et MiLićEvić Jasmina, «Combien d'acceptions le mot keuz "regret" a-t-il ? (Lexémisation du vocable keuz) », n 18, 2014, p. 205-226.

Coumert Magali, «Existe-t-il une "ancienne loi des Bretons d'Armorique" ? Identités ethniques et tradition manuscrite au haut Moyen Âge », n 18,2014 , p. 227-264.

\section{La Bretagne linguistique, $n^{\circ}$ 19, 2015}

GALL Laurent, «Kant plantenn, kant anv. Inflorescence linguistique en Basse-Bretagne », $n^{\circ} 19,2015$, p. 7-25.

Poli Muriel, «Quand la polysémie se généralise : le labre, le roitelet et l'euprocte se font "vieux". Les désignations relatives à la nature en langue corse $», n^{\circ} 19,2015$, p. 27-42.

GLON Thierry, «Esthétique du régionalisme », n 19, 2015, p. 43-54.

LySAGHT Ruth, «L'usage des langues minoritaires dans la production des émissions télévisuelles : une approche comparative des cas breton, irlandais et māori », $\mathrm{n}^{\circ} 19,2015$, p. 55-80.

Ò HifEARNAIN Tadhg, " La pratique de l'irlandais et la minorité irlandophone », $\mathrm{n}^{\circ} 19,2015, \mathrm{p} .81-97$.

LE DÛ Jean, " "J'étais un vrai âne" : réflexions d'un locuteur natif sur l'évolution de la pratique du gaélique irlandais au $\mathrm{Xx}^{\mathrm{e}}$ siècle », $\mathrm{n}^{\circ} 19$, 2015, p. 99-117.

RoBIN Thierry, « Flann O’Brien/Brian Ó Nualláin : portraits linguistiques d'un provocateur irlandais entre identité collective et idiosyncrasie ludique $», n^{\circ} 19,2015$, p. 119-137.

Dochy Amélie, «Pleasing, Emotionally Touching and Convincing: Erskine Nicol's Painting of Ireland and the Irish in the Mid-Nineteenth Century », n 19, 2015, p. 139-152.

Broudic Fañch, «Économie et langue bretonne : un rôle déterminant, deux fois ? », $\mathrm{n}^{\circ} 19,2015$, p. 153-203.

Costa WiLson James, «Toute langue est-elle commodifiable ? Quelques réflexions à partir de la situation actuelle du gaélique et de l'écossais en Écosse », n 19, 2015, p. 205-218.

LE SQUĖRE Roseline, "Comment les usages des marques de territoire et de la symbolique régionale bretonne peuvent-ils contribuer au développement de la langue bretonne et de la culture régionale ? ", $n^{\circ} 19,2015$, p. 219-237. 
Alcoufre Alain, «Économie et langue : le cas occitan », n 19, 2015, p. 239-259.

Jouitteau Mélanie, « Pronoms impersonnels dans le breton vannetais de Loeiz Herrieu. Syntaxe, sémantique et usages en concurrence avec le passif », $n^{\circ} 19,2015$, p. 261-280.

Chatelier Antoine, "La particule verbale "en" dans le standard de Vannes », n 19, 2015, p. 281-295.

Le PIPEC Erwan, «La palatalisation vannetaise », n 19, 2015, p. 297-327.

CARRE Daniel, "Courrier de guerre de Loeiz Herrieu à son épouse.

Considérations stylistiques et style épistolaire ", $\mathrm{n}^{\circ} 19,2015$, p. 329342.

Heulin Antony, «Loeiz Herrieu, de la langue des carnets à la langue littéraire », $\mathrm{n}^{\circ} 19,2015$, p. 343-361.

\section{La Bretagne linguistique, $\mathrm{n}^{\circ}$ 20, 2016}

Rodríguez María Fátima, "Bibliothèques captives. Politiques du livre dans les langues de l'État espagnol », $\mathrm{n}^{\circ}$ 20, 2016, p. 15-28.

PhiLIPPE Tanguy, " "Gleb" - Analyse croisée des registres sportifs et langagiers dans le cas du gouren/lutte bretonne ", $\mathrm{n}^{\circ} 20,2016$, p. 29-43.

Boudillet Estelle, «"Des étrangers et des gens du dehors". Ou quand les Johnnies ne s'appelaient pas Petit Jean », $\mathrm{n}^{\circ}$ 20, 2016, p. 45-88.

Fañch Postic et Nelly Blanchard, «Almanak Breiz-Izel (1872) : l'essai manqué d'un almanach républicain en breton », $n^{\circ} 20,2016$, p. 89124.

Crahé Maxime-Morvan, «Les occurrences de [ç] dans le parler de Languidic (breton haut-vannetais) $», n^{\circ} 20,2016$, p. 125-133.

SERIOT Patrick, « Les nations sont-elles de la compétence des linguistes?», $\mathrm{n}^{\circ} 20,2016$, p. 135-146.

Le BerRe Yves, Le Dû Jean, « Devoir et nécessité : à quoi sert le breton à ceux qui le parlent? », n² 20, 2016, p. 147-160.

Blanchard Nelly, Thomas Mannaig, « La carte des lieux. Connaissance et représentation de la géographie vernaculaire en breton », $\mathrm{n}^{\circ} 20,2016$, p. 161-180.

Broudic Fañch, «Actualité d’Emgleo Breiz ? », n² 20, 2016, p. 183-190.

Lespoux Yan, «Vidas. Création d'un dictionnaire biographique des acteurs de la renaissance d'oc en ligne : nécessité et contraintes », $\mathrm{n}^{\circ} 20,2016$, p. 191-198. 



\section{Index des articles parus dans les numéros 1 à 20 de La Bretagne linguistique ${ }^{1}$ Classement par ordre alphabétique d'auteur}

Avertissement : les articles signés par plusieurs auteurs apparaissent au nom de chacun d'entre eux.

AbJean René, «Le bilinguisme sur une radio de service public ", $\mathrm{n}^{\circ} 4$, 1989, p. 145-151.

AвRAHAm Maryvonne, « Le nom du chien en pays bretonnant», $\mathrm{n}^{\circ}$ 3, 1987, p. 107-116.

ADAM Catherine, «Élaboration d'une recherche en sociolinguistique sur les représentations parentales et leurs influences : le cas du bilinguisme scolaire breton-français du jeune enfant $», \mathrm{n}^{\circ} 18,2014$, p. 33-55.

AHLQvist Anders, « La situation sociolinguistique de l'irlandais », $\mathrm{n}^{\circ} 12$, 1998, p. 277-286.

AKIN Salih, «Représentations idéologiques et réalités langagières : le cas du kurde », n 10, 1996, p. 143-151.

Alcouffe Alain, «Économie et langue : le cas occitan », $n^{\circ}$ 19, 2015, p. 239-259.

Audic Armelle, «La langue bretonne à Arradon au $\mathrm{xx}^{\mathrm{e}}$ siècle. Essai de recherche ethno-socio-linguistique illustré par un exemple : C'hoari an Tri Roue hag ar Bassion », $\mathrm{n}^{\circ}$ 15, 2010, p. 7-27.

BALCOU Jean, «Ernest Renan et la langue bretonne », n 6, 1992, p. 69-78. BALIBAR Renée, "Langues internationales et minorités linguistiques ", $\mathrm{n}^{\circ} 8,1994$, p. 115-122.

BALIBAR Renée, «Colinguisme et dissonances. Les enjeux du travail des langues $», n^{\circ} 10,1996$, p. 27-32.

1. Afin d'alléger les références, nous n'indiquons dans cet index que le numéro du volume, l'année de publication et les pages et omettons volontairement le titre de la revue ( $L a$ Bretagne linguistique), la ville et le nom de l'éditeur (Brest, Centre de recherche bretonne et celtique) pour chaque occurrence. 
BALIBAR Renée, «La langue romane-française », n 11, 1998, p. 7-15.

BANKs David, «Transitivité systémique et analyse du texte », $\mathrm{n}^{\circ} 6,1992$, p. 45-52.

BARRÉ Ronan, "Langue et économie : quelques pistes de recherche ", $\mathrm{n}^{\circ} 14,2009$, p. 195-206.

BÉCHEREL Danielle, «Restrictions sémantiques dans la transformation adjectif/substantif », $n^{\circ} 6,1992$, p. 255-261.

Benot Marcel, «Les élèves des cours moyens 1 et 2 de Milizac et la langue bretonne $», n^{\circ} 1,1985$, p. 168-177.

Benot Marcel, «Attitudes à l'égard de la langue bretonne ", n 3, 1987, p. 65-74.

BERnABÉ Jean, «Un regard nouveau sur la diglossie français-créole.

Esquisse d'une approche écosystémique des langues ", $\mathrm{n}^{\circ}$ 9, 1997, p. 7-18.

Bernier Gildas, «Phonologie du breton de Quiberon », n 8, 1994, p. 261271.

Blanchard Nelly, «L'utilisation pédagogique des textes du concours $A r$ Falz », n 13, 2004, p. 13-29.

Blanchard Nelly, «Le manuscrit autobiographique d'Hervé Burel : le peuple dit par lui-même ? », n 14, 2009, p. 93-105.

Blanchard Nelly, «Les doublets synonymiques chez Hervé Burel (1905) ou comment casser l'entre-soi », n 17, 2013, p. 161-180.

Blanchard Nelly, «Julien Godest, paysan autobiographe sous l'aile de Taldir-Jaffrennou », $\mathrm{n}^{\circ}$ 18, 2014, p. 7-31.

Blanchard Nelly, Thomas Mannaig, « La carte des lieux. Connaissance et représentation de la géographie vernaculaire en breton ", $\mathrm{n}^{\circ} 20,2016$, p. 161-180.

Nelly Blanchard, Fañch Postic, «Almanak Breiz-Izel (1872) : l'essai manqué d'un almanach républicain en breton », $\mathrm{n}^{\circ} 20$, 2016, p. 89-124.

Blanchet Philippe, «Regard sur la dynamique ethno-sociolinguistique actuelle de la Provence, ou quand l'identité fait reculer la diglossie », $\mathrm{n}^{\circ} 11,1998$, p. 17-31.

Bothorel-Witz Arlette, Huck Dominique, «La place des dialectes alsaciens dans un modèle variationnel : réflexions sur les notions de variétés et de normes », $\mathrm{n}^{\circ} 10,1996, \mathrm{p}$. 281-297.

Boudillet Estelle, " "Des étrangers et des gens du dehors". Ou quand les Johnnies ne s'appelaient pas Petit Jean », $\mathrm{n}^{\circ} 20$, 2016, p. 45-88.

Bougthon Zoë, «La standardisation continue de la langue française : l'apport des perceptions et attitudes langagières », $n^{\circ} 16,2011$, p. 37 57. 
Bourel Claude, «Présentation d'un conte de Haute-Bretagne : Le cheval noir et le vagabond (approche linguistique et symbolique), $\mathrm{n}^{\circ} 4,1989$, p. $169-174$.

BRASSEUR Patrick, «Attitudes linguistiques des Normannophones dans les Îles anglo-normandes $», n^{\circ}$ 5, 1991, p. 111-127.

BRoudic François, « La pratique du breton aujourd'hui : approche méthodologique des problèmes d'évaluation $», \mathrm{n}^{\circ} 1,1985, \mathrm{p}$. 73-80.

BRoudic Fañch, «L'usage abusif du breton en 1902 : le point de vue du clergé », n 6, 1992, p. 103-142.

BRoudic Fañch, "Réalisation d'une enquête sur la pratique du breton », $\mathrm{n}^{\circ} 7,1993$, p. 215-222.

BRoudic Fañch, «Langues parlées, langues écrites en Basse-Bretagne, 1946-1990», n 10, 1996, p. 69-79.

BRoudic Fañch, « La recherche sur la pratique du breton : objet, méthodes et perspectives », $\mathrm{n}^{\circ} 11,1998$, p. 51-75.

BRoudic Fañch, «La faute à l'abbé Grégoire ?», n 12, 1998, p. 219-228.

BROUDIC Fañch, «La perception de la variation diatopique au fil du temps », $\mathrm{n}^{\circ} 13,2004$, p. 31-52.

BROUDIC Fañch, «Les nouveaux sondages sur la pratique du breton et celle de l'occitan en Aquitaine », n 15, 2010, p. 185-193.

BRoudic Fañch, «Économie et langue bretonne : un rôle déterminant, deux fois? », $\mathrm{n}^{\circ} 19,2015$, p. 153-203.

Broudic Fañch, «Actualité d'Emgleo Breiz ? », n² 20, 2016, p. 183-190.

BRoudic Jean-Yves, "Changement linguistique et processus psychiques inconscients liés à un trauma collectif : le cas de la Basse-Bretagne », $\mathrm{n}^{\circ} 15,2010$, p. 109-116.

Brun-Trigaud Guylaine, «À propos des atlas linguistiques régionaux. Problèmes de comparabilité », $\mathrm{n}^{\circ} 11,1998$, p. 33-49.

BRun-Trigaud Guylaine, « La limite oc-oïl : un débat franco-allemand », $\mathrm{n}^{\circ} 12,1998$, p. $75-82$.

BRUn-TRIgaud Guylaine, « Le breton : un éclairage sur l'histoire des parlers gallo-romans? », $\mathrm{n}^{\circ} 13,2004$, p. 53-71.

BRun-Trigaud Guylaine, "Le Thesaurus Occitan, une base de données multimédiale dédiée aux dialectes occitans $», \mathrm{n}^{\circ} 18,2014$, p. 57-72.

BRUNET-HunAUlt Laurence, "Imaginaire linguistique et acquisition de la langue $», \mathrm{n}^{\circ} 10,1996$, p. 265-272.

BuCKLEY Thomas, " La frontière linguistique breton-gallo dans les environs de Plouha », n 3, 1987, p.169-175.

CAdic Mireille, Plourin Jean-Yves, « Aspects linguistiques de l'émigration langonnetaise vers l'Amérique ", n² 2, 1986, p. 82-86. 
CADIOU Hervé, « Les colloques français-breton à la croisée des rapports du français et du breton », $\mathrm{n}^{\circ} 1,1985$, p. 125-131.

CAdiou Hervé, «À propos d'orthographe », n 3, 1987, p. 117-124.

CADIou Hervé, «Y a-t-il eu une influence de la langue écrite sur le parler du Léon ?», n 7, 1993, p. 223-226.

CAHUzac Philippe, "Approche théorique et pratique de quelques problèmes posés à la recherche lexicographique d'aujourd'hui ", $\mathrm{n}^{\circ} 3$, 1987, p. 77-93.

CAhuzac Philippe, « Badumes, standards, normes. La situation en Amérique hispanique $», \mathrm{n}^{\circ} 10,1996$, p. 309-318.

Caitucoli Claude, Sanogo Mamado L., Tsekos Nicolas, «Le PasseMuraille. Réalités langagières au Burkina Faso et en Grèce », $\mathrm{n}^{\circ} 10$, 1996, p. 105-122.

CALvez Ronan, " "Les Bretons parlent aux Bretons". Radio-Quimerc'h :

les débuts de la radio en breton $", \mathrm{n}^{\circ} 11,1998$, p. 97-113.

CALVEz Ronan, « Vie et mort du paysanisme breton : Feiz ha Breiz (18651875) $», n^{\circ} 11,1998$, p. 77-96.

CALVEz Ronan, « La métaphore mondaine. Kerenveyer et les littératures du breton », $\mathrm{n}^{\circ} 14,2009$, p. 25-40.

CALvez Ronan, "Amours cachées : la nouvelle rhétorique mondaine bretonne », $\mathrm{n}^{\circ} 17,2013$, p. 127-139.

Calvez Ronan, « Les mots et les causes. Du Dictionnaire de Coëtanlem », $n^{\circ} 17,2013$, p. 15-24.

Calvez Ronan, « Les mots et les sources », n 17, 2013, p. 81-109.

CAnobbio Sabina, «L'Atlas Linguistique comme outil de recherche ? À propos de quelques expériences italiennes ", $\mathrm{n}^{\circ} 13$, 2004, p. 281-312.

CARney Sébastien, «Célestin Lainé et le breton : la langue pour le combat », $n^{\circ} 16,2011$, p. 151-197.

CARPItelli Elisabetta, Le Bris Daniel, « Concordances linguistiques entre aires celtique et romane à partir des données des atlas multilingues ", $\mathrm{n}^{\circ} 18,2014$, p. 73-85.

CARRÉ Daniel, "Courrier de guerre de Loeiz Herrieu à son épouse. Considérations stylistiques et style épistolaire », $\mathrm{n}^{\circ} 19,2015$, p. 329342.

CASSARD Jean-Christophe, "Le breton dans la bd franco-belge », $\mathrm{n}^{\circ} 15$, 2010, p. 195-223.

Chatelier Antoine, "La particule verbale "en" dans le standard de Vannes », $\mathrm{n}^{\circ} 19,2015$, p. 281-295.

Chauveau Jean-Paul, "Quelques emprunts du gallo au breton », $\mathrm{n}^{\circ} 1$, 1985, p. 191-204. 
Chauveau Jean-Paul, « Le Französisches Etymologisches Wörterbuch de Walter von Wartburg et son intérêt pour des celtisants », n 9, 1997, p. 19-37.

Chetouani Lamria, «Lexicométrie et débats politiques sur l'environnement », $n^{\circ}$ 9, 1997, p. 39-64.

Cheveau Loic, «Le breton de Ploemeur d'après l'ALBB de P. Le Roux : lecture critique $», \mathrm{n}^{\circ} 15,2010$, p. 29-42.

Choplin Cédric, «Feiz ha Breiz (1865-1884) ou la genèse d'une langue journalistique $», \mathrm{n}^{\circ} 16,2011$, p. 19-35.

Clairis Christos, "La réforme linguistique en Turquie », $\mathrm{n}^{\circ}$ 10, 1996, p. 153-157.

CoËTAnlem Pierre-Joseph-Jean, « Préface », n 17, 2013, p. 7-14.

Costa WiLson James, « Toute langue est-elle commodifiable ? Quelques réflexions à partir de la situation actuelle du gaélique et de l'écossais en Écosse », n 19, 2015, p. 205-218.

Costaouec Denis, « Sociolinguistique et étude des changements linguistiques en synchronie $», \mathrm{n}^{\circ} 11,1998$, p. 115-119.

Costaouec Denis, «Contraintes et libertés en phonologie : neutralisations et faits d'assimilation en breton », $\mathrm{n}^{\circ} 15,2010$, p. 123-145.

Coumert Magali, "Existe-t-il une "ancienne loi des Bretons d'Armorique" ? Identités ethniques et tradition manuscrite au haut Moyen Âge », $n^{\circ} 18,2014$, p. 227-264.

CrahÉ Maxime-Morvan, «Les occurrences de [ç] dans le parler de Languidic (breton haut-vannetais) $», \mathrm{n}^{\circ} 20,2016, \mathrm{p} .125-133$.

CroIX Alain, « Langues du peuple, langues pour le peuple. Les langages des missions bretonnes au dix-septième siècle », $\mathrm{n}^{\circ}$ 4, 1989, p. 155167.

Dalbera Jean-Philippe, « Espace et variation linguistique : description et modélisation. Les bases de données THESOC et ALCANOM », $\mathrm{n}^{\circ} 11$, 1998, p. 121-134.

Dalbera-Stefanaggi Marie-José, «La base de données dialectales : un instrument de sauvegarde et de recherche. L'exemple corse $», \mathrm{n}^{\circ} 11$, 1998, p. 135-152.

Dell'aquila Vittorio, Iannaccaro Gabriele, «Quelques considérations sur la cartographie des données linguistiques », $\mathrm{n}^{\circ} 17,2013$, p. 253-286.

Deprez Kas, Wynants Armel, « Fouron : insoluble ? », n³ 3, 1987, p. 177207.

Deprez Kas, « Soldats du Néerlandais », n 10, 1996, p. 189-215.

Deprez Kas, « Pourquoi la langue officielle de la Flandre n'est-elle pas le flamand, mais le néerlandais? », $\mathrm{n}^{\circ} 12,1998$, p. 287-322. 
Desseigne Adrien, Kersulec Pierre-Yves, « Les enquêtes dialectologiques de la Société d'Ethnolinguistique Bretonne : éléments de présentation du Questionnaire grammatical $1500 », n^{\circ} 18,2014$, p. 87-109.

Dосну Amélie, «Pleasing, Emotionally Touching and Convincing: Erskine Nicol's Painting of Ireland and the Irish in the Mid-Nineteenth Century », n 19, 2015, p. 139-152.

Eloy Jean-Michel, « La langue est de nature sociale ", n 8, 1994, p. 209222.

Eloy Jean-Michel, "La République et les registres langagiers ", $\mathrm{n}^{\circ} 10$, 1996, p. 33-56.

Eloy Jean-Michel, «Dans quel sens peut-on dire que le picard est une langue minoritaire ?», $\mathrm{n}^{\circ} 11,1998$, p. 153-168.

Eloy Jean-Michel, « La fille aînée du latin... est restée célibataire trop longtemps », $\mathrm{n}^{\circ} 12,1998, \mathrm{p} .117-140$.

Evenou Yvon, « Oppositions de longueur vocalique et formes canoniques dans le breton de Lanvenegen (canton du Faouët) », n 1, 1985, p. 179189.

Evenou Yvon, «La proposition dite relative dans le breton de Lanvénégen », n 4, 1989, p. 121-129.

Evenou Yvon, "Breton et culture bretonne dans l'éducation nationale », $\mathrm{n}^{\circ} 8,1994$, p. 145-154.

FAGON Christian, « Changement du/z/ en / $/$ / en Léon : continuité du brittonique au breton moderne et regard sociolinguistique des locuteurs sur ce phénomène $», n^{\circ} 13,2004, p .73-83$.

FALC'HUN François, "La structure linguistique du domaine bretonnant », $\mathrm{n}^{\circ} 1,1985$, p. $59-71$.

FALC'HUN François, «Introduction à une étude des noms de lieux celtiques de la Mayenne, d'après le Dictionnaire topographique du département par Léon Maître (1878) », n² 2, 1986, p. 37-39.

FALL Khadiyatoulah, "Le jeu des identités ou la plasticité du lexème “intégration" ", n 11, 1998, p. 169-177.

FAUQUeT Eric, « La question de la génialité de la langue. Transfert des idées de Herder en France », n 11, 1998, p. 179-186.

FAVEREAU Francis, «Quatre générations de bretonnants », $n^{\circ}$ 7, 1993, p. 3152.

FAVEREAU Francis, « Normalisation d'un conte breton : à la recherche de l'impossible norme », n 10, 1996, p. 123-131.

FAVEREAU Francis, « Déictiques spatio-temporels en breton central », $\mathrm{n}^{\circ} 13$, 2004, p. 85-103. 
FAVEREAU Francis, « Le je(u) de chaises musicales du breton », n 14, 2009 , p. 227-239.

Flatrès Pierre, « Lang Kouter (lankouta) - L'argot des tailleurs d'Elliant (Finistère) », $\mathrm{n}^{\circ} 1$ 1, 1985, p. 137-141.

Flatres Pierre, «La toponymie orale comme témoignage d'une langue éteinte », n 3, 1987, p. 95-98.

Flatrès Pierre, «Anglo-Saxons, Anglo-Normands, Anglo-Français, Anglo-Celtiques $», n^{\circ} 6,1992$, p. 53-65.

Flatrès Pierre, "Abandon de langue et transmission de traditions : à propos de quelques rencontres avec le paganisme celtique $", \mathrm{n}^{\circ} 7$, 1993, p. 53-58.

Flatrès Pierre, «La notion de nation dans les Îles Britanniques », $\mathrm{n}^{\circ} 8$, 1994, p. 195-207.

FLEURIOT Léon, «Évolutions anciennes et récentes en breton », $\mathrm{n}^{\circ}$ 1, 1985, p. 87-97.

FolLEt Jean-Philippe, «Essai de recherche ethnotextuelle à l'Île de Batz (Finistère) $», n^{\circ} 1,1985$, p. 81-83.

FolLET Jean-Philippe, « Île de Batz : le paysage sociolinguistique au début des années $1980 », \mathrm{n}^{\circ} 15,2010$, p. 146-159.

GACHELIN Jean-Marc, " Le purisme en général, et anglo-saxon en particulier », $\mathrm{n}^{\circ} 11,1998$, p. 187-202.

GACHELIN Jean-Marc, « Un aperçu du lexique de l'anglais dialectal », $\mathrm{n}^{\circ} 13$, 2004, p. 313-330.

GALl Laurent, "Kant plantenn, kant anv. Inflorescence linguistique en Basse-Bretagne », $\mathrm{n}^{\circ}$ 19, 2015, p. 7-25.

Gallard Philippe, « Imaginaire linguistique et français dialectal du Poitou : le sentiment identitaire chez les jeunes », $n^{\circ} 10,1996$, p. 273-279.

GALliou Patrick, «L'Armorique romaine : assimilation ou résistance ? », $\mathrm{n}^{\circ} 1,1985$, p. 205-221.

Galliou Patrick, TANGUY Bernard, «Armorican graffiti - prolégomènes à l'étude des graffites romains d'Armorique », n 4, 1989, p. 79-83.

Garcia-Mendez Javier, "Parité et disparité parolières dans le roman hispano-américain », $\mathrm{n}^{\circ} 10,1996$, p. 299-308.

García-Mouton Pilar, "Sur la dialectologie espagnole », $\mathrm{n}^{\circ}$ 13, 2004, p. 331-340.

GARDY Philippe, « Le domaine occitan depuis vingt ans : pratiques linguistiques et revendications, $n^{\circ} 4,1989$, p. 99-115.

GARDY Philippe, "Le personnage du Franchimand comme interlangue ", $\mathrm{n}^{\circ}$ 5, 1991, p. 41-49. 
GARDY Philippe, «"De l'accordéon (français ?)” Badume, Standard, Norme dans la diglossie franco-occitane ( $\mathrm{XVI}^{\mathrm{e}}-\mathrm{XVIII}{ }^{\mathrm{e}}$ siècles). Imaginaire linguistique et dynamique langagière Aspects théoriques et méthodologiques », $\mathrm{n}^{\circ} 10,1996$, p. 329-347.

GARDY Philippe, «Une étrange aversion? Jean Giono écrivain, "analyseur" de la situation sociolinguistique française ? », $\mathrm{n}^{\circ} 12,1998$, p. 175-194.

GeFrroy Annie, «La lexicométrie : pour une approche mesurée du discours $», n^{\circ} 10,1996$, p. 371-383.

George Kenneth J., « Le cornique : un cinquième dialecte du breton ? ", $\mathrm{n}^{\circ} 1,1985$, p. $117-124$.

George Kenneth J., «Un exemple de bilinguisme breton-anglais », $\mathrm{n}^{\circ} 2$, 1986, p. 150-158.

George Kenneth J., "Quelques réflexions sur l'ordre des mots dans la pièce en moyen breton Buhez Santez Nonn », n 4, 1989, p. 175-187.

GERMAN Gary, «L'histoire phonologique du déterminant défini et indéfini

à Saint-Yvi en Cornouaille selon les observations faites par De Jubainville à Fouesnant en $1874 », n^{\circ} 3,1987$, p. 157-168.

GERMAN Gary, «Une méthode dialectométrique (assistée par ordinateur) pour l'analyse des atlas linguistiques », $\mathrm{n}^{\circ}$ 7, 1993, p. 177-213.

GERMAN Gary, «Langue et identité : une enquête sociolinguistique menée dans huit écoles galloises portant sur les attitudes envers le gallois et l'anglais », $\mathrm{n}^{\circ} 11,1998$, p. 203-205.

German Gary, «Analyse diachronique et variationniste de la désinence du pluriel -EN en anglais standard et non standard $», n^{\circ} 13,2004$, p. 105127.

German Gary, " "Badume, Standard et Norme" à la lumière de l'anglais vernaculaire des Appalaches », $\mathrm{n}^{\circ}$ 15, 2010, p. 83-107.

Giraudon Daniel, « Ornithonymes et breton populaire. Des cris, des couleurs, des mœurs et des genres », $\mathrm{n}^{\circ} 13,2004$, p. 105-127.

GiRAUDON Daniel, «Les blasons populaires en Bretagne », $n^{\circ}$ 15, 2010, p. 161-168.

GLON Thierry, «Esthétique du régionalisme », n 19, 2015, p. 43-54.

Goebl Hans, « Trois coups d'œil rapides sur la situation sociolinguistique dans les Alpes centrales - Grisons, Tyrol du Sud/Haut-Adige, Carinthie méridionale », $\mathrm{n}^{\circ}$ 8, 1994, p. 165-193.

Goebl Hans, « Brève présentation de l'Atlas linguistique ladin (ALD 1ère et $2^{\mathrm{e}}$ partie) $», \mathrm{n}^{\circ} 13,2004$, p. 375-381.

GouletQuer Pierre, «Des pierres et des mots ; quelques aspects des convergences entre archéologie et linguistique $», \mathrm{n}^{\circ} 3,1987, \mathrm{p} .145-155$. 
GouletQuer Pierre, «Archéologie intégrée - la recherche archéologique et ses facteurs déterminants : l'exemple du Finistère ", n 4, 1989, p. 33-51.

GouletQuer Pierre, «Opacité sémantique et discontinuité de l'information archéologique », $n^{\circ} 6,1992$, p. 253-254.

Gouletquer Pierre, "Barnenez-ar-Zant et ses symboles », $\mathrm{n}^{\circ}$ 7, 1993, p. 103-133.

Gouletquer Pierre, «Cadastre napoléonien, archéologie et territoires parlés », n 11, 1998, p. 207-212.

Gouletquer Pierre, "Géographie linguistique et archéo-géographie; plaidoyer pour des démarches interdisciplinaires ", $\mathrm{n}^{\circ} 11,1998$, p. 213-225.

Goyat Gilles, « Prosodie et prosodie musicale », $\mathrm{n}^{\circ}$ 9, 1997, p. 65-76.

Goyat Gilles, « La deuxième personne dans le parler breton de Plozévet », $\mathrm{n}^{\circ} 13,2004$, p. 129-138.

Goyat Gilles, « La langue bretonne dans la Mission de folklore musical de Basse-Bretagne de 1939, n 16, 2011, p. 87-96.

Guillorel Éva, «Le Barzaz Bro-Leon, ou la tentative d'un nouveau Barzaz-Breiz: premières approches d'un fonds inédit de près de 1000 chansons en breton », $\mathrm{n}^{\circ} 14,2009, \mathrm{p} .81-92$.

Guillou Anne, « Les femmes et le breton », n 11, 1998, p. 227-231.

GuIOMAR Jean-Yves, « Les historiens et la langue bretonne au XIX ${ }^{\mathrm{e}}$ siècle », $\mathrm{n}^{\circ} 1,1985$, p. 99-102.

Guiomar Jean-Yves, «L'introduction en France des idées sur l'origine celtique de la littérature française par l'Abbé Gervais de La Rue ", $\mathrm{n}^{\circ} 8,1994$, p. 7-89.

GuYONVARC' H Christian-Joseph, « Dialectes et moyen-breton », nº 1, 1985, p. 133- 135.

Guyonvarc'H Christian-Joseph, «La langue gauloise dans le De Bello gallico », $\mathrm{n}^{\circ} 6,1992, \mathrm{p} .239-251$.

Hellegouarc' H Anne, « Cymuned - aux grands maux les grands remèdes », $n^{\circ} 15,2010$, p. 225-247.

Hemprich Gisbert, Tristram Hildegard L. C., «Esquisse de la situation linguistique actuelle de Fribourg-en-Brisgau (Allemagne) », $\mathrm{n}^{\circ} 10$, p. 177-188.

Heulin Antony, «Loeiz Herrieu, de la langue des carnets à la langue littéraire », $\mathrm{n}^{\circ} 19,2015$, p. 343-361.

HEwITT Stephen, «Quelques ressemblances structurales entre le breton et l'arabe : conséquence d'une typologie ordinale commune ? », $\mathrm{n}^{\circ} 1$, 1985, p. 223-262. 
HewitT Steve, «Le progressif en breton à la lumière du progressif anglais $», n^{\circ} 2,1986$, p. 133-148.

Hewitt Steve, "Réflexions et propositions sur l'orthographe du breton », $\mathrm{n}^{\circ} 3,1987$, p. 41-54.

HewitT Steve, «Un cadre descriptif pour la syntaxe du verbe breton », $\mathrm{n}^{\circ} 4,1989$, p. 203-211.

Hobe-Canut Cécile, «Imaginaire linguistique au Mali », n 10, 1996, p. 257-264.

HoRIOt Brigitte, « Le travail de dialectologie dans le domaine de l'ALO », $\mathrm{n}^{\circ} 2,1986$, p. 98-106.

Houdebine Anne-Marie, «Imaginaire linguistique et dynamique langagière. Aspects théoriques et méthodologiques ", n 10, 1996, p. 239255.

Huck Dominique, Bothorel-Witz Arlette, «La place des dialectes alsaciens dans un modèle variationnel : réflexions sur les notions de variétés et de normes », $\mathrm{n}^{\circ} 10,1996$, p. 281-297.

Hughes Arthur John, «Les mots qui désignent le cheval dans les langues gaéliques du point de vue de la géographie linguistique », $\mathrm{n}^{\circ} 8,1994$, p. 223-259.

Humphreys Humphrey Lloyd, « Projet d'un dictionnaire de la prononciation des toponymes bretons (DPTB) », $\mathrm{n}^{\circ} 2,1986$, p. 9-23.

HumPHREYs Humphrey Lloyd, «Présentation des hebdomadaires de langue galloise $», n^{\circ} 8,1994$, p. 99-104.

HumPHREYs Humphrey Lloyd, «Présentation des hebdomadaires de langue galloise $», \mathrm{n}^{\circ}$ 9, 1997, p. 77-81.

HuMPhREYs Humphrey Lloyd, " Réflexions sur les localismes et le supralocalisme en anglais, en gallois et en breton », $\mathrm{n}^{\circ} 10,1996$, p. 81-95.

IANNACCARo Gabriele, Dell'aquila Vittorio, «Quelques considérations sur la cartographie des données linguistiques », $\mathrm{n}^{\circ} 17,2013$, p. 253-286.

IRSLINGER Britta, « Les dérivés gallois, cornique en -yn / -en, breton en -enn et irlandais en -ne : fonction et sémantique », $\mathrm{n}^{\circ} 15,2010$, p. 43-81.

IsAAC Luc, «Aspects de la question linguistique en Belgique », $\mathrm{n}^{\circ}$ 9, 1997, p. 83-98.

Jones Mari, «Le parler des jeunes : nouvelle norme pour le siècle prochain ?», n 10, 1996, p. 159-168.

JøRGENSEN Anders Richardt, " On Breton "meliner" (miller) and other agent noun derivatives with Latin "ator" », n 14, 2009, p. 207-226.

JøRGENSEN Anders Richardt, « On the sources and transmission of the Early Vannetais noels $», n^{\circ} 17,2013$, p. 203-231. 
JouitTeau Mélanie, Rezac Milan, « Le verbe "avoir" à travers les dialectes du breton », n 14, 2009, p. 115-141.

Jouitteau Mélanie, « Pronoms impersonnels dans le breton vannetais de Loeiz Herrieu. Syntaxe, sémantique et usages en concurrence avec le passif », $n^{\circ} 19,2015$, p. 261-280.

KALYGUINE Victor, "La poétique irlandaise archaïque du point de vue mythologique. Domestication de l'espace », n 8, 1994, p. 135-143.

Kersulec Pierre-Yves, «Les noms en -erezh à référence collective : esquisse de classement $», n^{\circ} 15,2010$, p. 249-274.

Kersulec Pierre-Yves, Desseigne Adrien, « Les enquêtes dialectologiques de la Société d'Ethnolinguistique Bretonne : éléments de présentation du Questionnaire grammatical $1500 », n^{\circ} 18,2014$, p. 87-109.

KerYell Gaela, " La communauté des locuteurs citoyens et la communauté des locuteurs parents, nationalisme "politique" et nationalisme "culturel" ", n 12, 1998, p. 243-275.

Kretzschmar William A., «Vingt années de l'American Linguistic Atlas Project $\gg, n^{\circ} 13,2004$, p. 383-400.

KRIER Fernande, «Le trilinguisme au Luxembourg », $\mathrm{n}^{\circ}$ 7, 1993, p. 7-20.

KRIER Fernande, «La diversité dans l'unité : les langues minoritaires », $\mathrm{n}^{\circ} 10,1996$, p. 231-237.

L'HourRe Ronan, « Le changement de langue (en Basse-Bretagne) : pour une approche centrée sur le sujet parlant $», \mathrm{n}^{\circ} 11,1998$, p. 253-271.

LAFONT Robert «Langues en contact / langues en conflit; trente ans de sociolinguistique périphérique : cinq concepts revisités ", $\mathrm{n}^{\circ} 12,1998$, p. 27-38.

LAMBERT Pierre-Yves, « Nouvelles orientations de la recherche dans l'étude des gloses celtiques (en particulier brittoniques) », $\mathrm{n}^{\circ} 3,1987$, p. 99105.

LAMBERT Pierre-Yves, «La situation linguistique de la Bretagne au Haut Moyen Âge », n 5, 1991, p. 139-151.

LAMPLE Bernard, "Les pêcheurs kerhorres : une communauté originale dans la rade de Brest », $n^{\circ} 8,1994$, p. 123-134.

LAROUSSI Foued, « Frontières linguistiques et pratiques langagières : Le cas tunisien $», n^{\circ} 10,1996$, p. 133-142.

LaURent Donatien, «La troménie de Locronan. La fête de Lughnasa et le calendrier celtique », $\mathrm{n}^{\circ} 3,1987$, p. 127-143.

Le Berre Annie, "Problèmes d'étude d'un français urbain de BasseBretagne : le parler de Brest », n 1, 1985, p. 39-46.

Le Berre Annie, « Réflexions sur la section "sociolinguistique et ethno- 
linguistique" du bulletin signalétique du CNRS (sciences du langage) : reflets d'un partage du monde », $\mathrm{n}^{\circ} 2,1986$, p. 70-80.

LE BERRE Annie, « Bretagne : terre incognita? À propos d'une enquête sur la connaissance de la Bretagne dans une classe de première brestoise, année scolaire 1987-1988», n 5, 1991, p. 197-218.

LE BERRE Yves, «Recherche : problématique et méthodologie », $\mathrm{n}^{\circ} 1$, 1985, p. 31- 37.

Le Berre Yves, «Un 'Supplément' au Livr el labourer de Joachim Guillôme », n 6, 1992, p. 159-174.

Le BERRE Yves, «L'écriture du breton dans l'histoire. Essai de synthèse », $\mathrm{n}^{\circ}$ 7, 1993, p. 153-176.

Le Berre Yves, «À propos du Stabat Mater breton de Tanguy Guéguen (1622) : le "moyen-breton" existe-t-il ? », n 14, 2009, p. 13-24.

Le Berre Yves, "La force et l'élégance. Les litotes dans la Passion bretonne de $1530 », n^{\circ} 16,2011$, p. 123-149.

Le Berre Yves, « Présentation de la journée du 11 février 2011 », n 17, 2013, p. 125-126.

Le Berre Yves, « Rhétorique des gwerziou », n 17, 2013, p. 141-160.

Le Berre Yves, Le Dû Jean, «L'élaboration d'une banque de données textuelles du breton », nº 9, 1997, p. 99-104.

Le Berre Yves, Le Dû Jean, « Parité et disparité. Sphère publique et sphère privée de la parole $», n^{\circ} 10,1996$, p. 7-25.

Le Berre Yves, Le Dû Jean, «Faits de langues, faits de sociétés », n 11 , 1998, p. 233-243.

Le Berre Yves, Le Dû Jean, «Y a-t-il une exception sociolinguistique française ? », n 12, 1998, p. 11-26.

Le BerRe Yves, Le Dû Jean, « Devoir et nécessité : à quoi sert le breton à ceux qui le parlent? », $\mathrm{n}^{\circ}$ 20, 2016, p. 147-160.

Le Besco Patrick, "Le breton de Belle-Île-en-Mer, quelques caractéristiques », $n^{\circ} 7,1993$, p. 141-149.

Le Besco Patrick, «L'argot des maçons de la Forêt-Fouesnant », n ${ }^{\circ}$, 1994, p. 105-106.

LE BrIS Daniel, «Les études linguistiques d'Edward Lhuyd en Bretagne en $1701 », n^{\circ} 14,2009$, p. 175-193.

Le Bris Daniel, « Entre Penzé et Rivière de Morlaix : termes nautiques bretons relevés par Coëtanlem », n 17, 2013, p. 111-123.

Le Bris Daniel, CARPITElli Elisabetta, "Concordances linguistiques entre aires celtique et romane à partir des données des atlas multilingues ", $\mathrm{n}^{\circ} 18,2014$, p. $73-85$. 
LE Dû Jean, «Dialectologie et géographie linguistique de la BasseBretagne $», n^{\circ} 1,1985$, p. 145-167.

LE Dû Jean, « Pourquoi avons-nous créé le GRELB ? », nº 1, 1985, p. 2130.

LE Dû Jean, « Pour un Atlas linguistique collectif de la langue bretonne », $\mathrm{n}^{\circ}$ 7, 1993, p. 21- 30.

LE Dû Jean, « Introduction : La dialectologie et la géolinguistique bougent encore! », $\mathrm{n}^{\circ} 13,2004$, p. 5-11.

LE Dû Jean, "Thésaurus des noms de poissons d'animaux marins et du bord de mer des côtes de Basse-Bretagne ", $\mathrm{n}^{\circ}$ 14, 2009, p. 69-79.

LE Dû Jean, « Un atlas linguistique du créole des Petites Antilles (ALPA) » $\mathrm{n}^{\circ} 16,2011$, p. $59-74$.

LE Dû Jean, " "J'étais un vrai âne" : réflexions d'un locuteur natif sur l'évolution de la pratique du gaélique irlandais au $\mathrm{Xx}^{\mathrm{e}}$ siècle $», \mathrm{n}^{\circ} 19$, 2015, p. 99-117.

Le Dû Jean, Le Berre Yves, «L'élaboration d'une banque de données textuelles du breton », n 9, 1997, p. 99-104.

Le Dû Jean, Le Berre Yves, « Parité et disparité. Sphère publique et sphère privée de la parole », $\mathrm{n}^{\circ} 10,1996, \mathrm{p} .7-25$.

Le Dû Jean, Le Berre Yves, « Faits de langues, faits de sociétés », n 11, 1998, p. 233-243.

Le Dû Jean, Le Berre Yves, "Y a-t-il une exception sociolinguistique française ? », n 12, 1998, p. 11-26.

Le Dû Jean, Le Berre Yves, « Devoir et nécessité : à quoi sert le breton à ceux qui le parlent? », n² 20, 2016, p. 147-160.

Le Duc Gwenaël, «La Vie de Geneviève de Brabant : la langue comme écran et révélateur », $\mathrm{n}^{\circ} 1,1985$, p. 263-275.

Le Duc Gwenaël, "La lettre d'un recteur de Muzillac à sa servante (1793)», n6, 1992, p. 143-158.

LE GALL Laurent, « La Bretagne, une illusio qui fonctionne », $\mathrm{n}^{\circ}$ 18, 2014, p. 11-136.

Le GuIRRIEC Patrick, «La nomenclature des termes de référence en Bretagne $», n^{\circ} 5,1991$, p. 51-56.

Le Monze Sylvie, «Tutoiement, vouvoiement et autres formes d'adresse en français de Bretagne », $\mathrm{n}^{\circ} 11,1998$, p. 245-251.

Le PiPec Erwan, «Lecture critique du Nouvel Atlas Linguistique de la Basse-Bretagne », $\mathrm{n}^{\circ}$ 13, 2004, p. 157-175.

Le PiPec Erwan, «La phrase négative en breton : de la phonologie à la syntaxe $», n^{\circ} 14,2009$, p. 57-67. 
LE PIPEC Erwan, « Le breton, langue-totem ? », n 18, 2014, p. 137-176.

LE PIPEC Erwan, « La palatalisation vannetaise », $n^{\circ} 19,2015$, p. $297-$ 327.

Le Roc'h-Morgère Louis, « Sur Charlemagne et les douze pairs de France, tragédie bretonne du XVII siècle », $\mathrm{n}^{\circ} 4,1989$, p. 117-119.

Le Rol Jean-Paul, "La Passion de Pleudaniel : étude linguistique et sociolinguistique $», \mathrm{n}^{\circ} 15,2010, \mathrm{p} .117-122$.

Le RouzIC Suzanne, «Une mutation linguistique en trois étapes », $\mathrm{n}^{\circ} 5$, 1991, p. 103-109.

Le Rouzic Suzanne, «Un écrivain de langue bretonne l'Abbé Pierre Noury : 1743-1804», n 8, 1994, p. 107-111.

LE RUYET Jean-Claude, « Effet Buben, liaison et modèles orthographiques bretons $», \mathrm{n}^{\circ} 16,2011$, p. 97-109.

Le SQuère Roseline, «Comment les usages des marques de territoire et de la symbolique régionale bretonne peuvent-ils contribuer au développement de la langue bretonne et de la culture régionale ? ", $\mathrm{n}^{\circ} 19,2015$, p. 219-237.

LeCOCQ Jean-Marc, « Les mots d'origine bretonne dans l'argot français », $\mathrm{n}^{\circ} 7,1993$, p. 227-238.

LeCOCQ Jean-Marc, « Les argots bretons, langages secrets professionnels en Basse-Bretagne », $\mathrm{n}^{\circ}$ 8, 1994, p. 155- 162.

LEDUNOIS Jean-Pierre, « Grammaire et dialectologie », n 13, 2004, p. 139156.

LÉONARD Jean Léo, « Diasystème et diglossie périphérique : le "cas galloroman" ", n 12, 1998, p. 141-174.

Lespoux Yan, «Vidas. Création d'un dictionnaire biographique des acteurs de la renaissance d'oc en ligne : nécessité et contraintes », $\mathrm{n}^{\circ} 20,2016$, p. 191-198.

LoDGE Anthony, « En quoi pourrait consister l'exception sociolinguistique française ? », $\mathrm{n}^{\circ} 12,1998$, p. 59-74.

Louis François, MiLićević Jasmina, « Combien d'acceptions le mot keuz "regret" a-t-il ? (Lexémisation du vocable keuz)», $\mathrm{n}^{\circ}$ 18, 2014, p. 205-226.

LysAght Ruth, "L'image des langues minoritaires à travers les médias contemporains », $\mathrm{n}^{\circ} 17,2013$, p. 233-252.

LysAGHT Ruth, «L'usage des langues minoritaires dans la production des émissions télévisuelles : une approche comparative des cas breton, irlandais et māori », $\mathrm{n}^{\circ} 19,2015$, p. 55-80.

Maas-Chauveau Claudia « Présentation des recherches en onomastique du Patronymia romanica $», \mathrm{n}^{\circ}$ 5, 1991, p. 99-102. 
Manzano Francis, «Identité et frontière : linéaments d'une recherche sur le contact normano-breton $», n^{\circ}$ 9, 1997, p. 105-125.

MARCELleSI Jean-Baptiste, «La sociolinguistique en France aujourd'hui : les tendances et les équipes », $\mathrm{n}^{\circ} 2,1986, \mathrm{p} .110-122$.

MARCELlesi Jean-Baptiste, "Contribution à l'histoire de la sociolinguistique : origines et développement de l'école rouennaise », $\mathrm{n}^{\circ} 12,1998$, p. 39-57.

Martel Philippe, "L'image de l'occitan dans l'opinion au XIX ${ }^{\mathrm{e}}$ siècle ", $\mathrm{n}^{\circ} 12,1998$, p. 195-217.

Megdiche Cyrille, «Approche sociologique des relations interethniques en milieu urbain $», n^{\circ} 11,1998$, p. 273-281.

Mekaoui Frédéric, «De la difficulté d'être soi-même entre France et Allemagne, entre modernité et tradition », $\mathrm{n}^{\circ}$ 12, 1998, p. 229-241.

MiLIĆEviĆ Jasmina, LouIs François, «Combien d'acceptions le mot keuz "regret" a-t-il ? (Lexémisation du vocable keuz) », n 18, 2014, p. 205-226.

Mouton Jacques-Yves, «Le mythe de Tir Na N-og chez les premiers Liammistes », $\mathrm{n}^{\circ} 14,2009$, p. 107-113.

NiLSEN Kenneth E., « Le gaélique en Nouvelle-Écosse », n 7, 1993, p. 7991.

NiLSEN Ken, « Le gaélique en Nouvelle-Écosse : survivance d'une langue orale au Nouveau Monde », $\mathrm{n}^{\circ}$ 10, 1996, p. 97-103.

NoAILly Michèle, «Autour du défini cataphorique », $\mathrm{n}^{\circ}$ 7, 1993, p. 93-102.

Ò HIFEARNAIN Tadhg, « La pratique de l'irlandais et la minorité irlandophone $», n^{\circ} 19,2015$, p. 81-97.

OMNÈs Robert, « Structures et modèles syllabiques », n 4, 1989, p. 53-78.

Philippe Tanguy, «Gleb - Analyse croisée des registres sportifs et langagiers dans le cas du gouren/lutte bretonne », $\mathrm{n}^{\circ} 20,2016$, p. 29-43.

PILCH Herbert, «L'accentuation de la langue bretonne », $n^{\circ} 2$ 2, 1986, p. 4368.

PILch Herbert, «L'intonation de la langue bretonne », n 6, 1992, p. 175182.

PINOT Jean-Pierre, « Noms donnés par les pêcheurs aux fonds sous-marins sur le plateau continental sud-armoricain », $\mathrm{n}^{\circ} 4,1989$, p. 85-95.

PIRIou Yann-Ber, « Notes de lecture : Les amours d'un vieillard », $\mathrm{n}^{\circ} 2$, 1986, p. 88-97.

PlonÉIs Jean-Marie, " Une autre lecture de l'histoire du monde rural », $\mathrm{n}^{\circ} 1,1985$, p. 47-50.

PlonÉIs Jean-Marie, «Toponymie : formes orales et écrites. Évolutions phonétiques $», \mathrm{n}^{\circ} 2,1986$, p. 31-35. 
PLoNÉIS Jean-Marie, « Le paysan et ses animaux. Quelques aspects linguistiques $», n^{\circ} 5,1991$, p. 69-76.

PLonÉIS Jean-Marie, «Toponymie : contribution à la dialectologie bretonne », $\mathrm{n}^{\circ} 8,1994$, p. 91-97.

PlÖTNER Bärbel, « La correspondance entre Hersart de La Villemarqué et un savant allemand, Jacob Grimm », n 6, 1992, p. 7-44.

Plourin Jean-Yves, "L'accentuation en Haute-Cornouaille et en BasVannetais $», \mathrm{n}^{\circ} 1,1985, \mathrm{p} .103-115$.

PlourIN Jean-Yves, CADIC Mireille, «Aspects linguistiques de l'émigration langonnetaise vers l'Amérique », $\mathrm{n}^{\circ} 2,1986$, p. 82-86.

Plourin Jean-Yves, « De quelques mots bretons anciens », $n^{\circ}$ 9, 1997, p. 127-135.

PLouRIN Jean-Yves, «La phrase bretonne comprenant le verbe ÊTRE au présent de l'indicatif. Conflits de topicalisation ", n 11, 1998, p. 283300 .

Plourin Jean-Yves, « La grammaire bretonne à l'épreuve des dialectes ", $\mathrm{n}^{\circ} 13,2004$, p. 177-193.

PLourin Jean-Yves, "Continu et discontinu dans le groupe nominal », $\mathrm{n}^{\circ} 14,2009$, p. 143-174.

PoLi Muriel, «Quand la polysémie se généralise : le labre, le roitelet et l'euprocte se font "vieux". Les désignations relatives à la nature en langue corse $», n^{\circ} 19,2015$, p. 27-42.

Postic Fañch, «Le fonds La Villemarqué : une source importante pour l'histoire de l'ethnographie et des études celtiques », $\mathrm{n}^{\circ} 15,2010$, p. 169-183.

Postic Fañch, « Les dictionnaires bretons, une source pour l'ethnographie : l'article "Eghinat" chez Coëtanlem et Le Pelletier », n 17, 2013, p. 25-64.

Fañch Postic, Nelly Blanchard, «Almanak Breiz-Izel (1872) : l'essai manqué d'un almanach républicain en breton », $\mathrm{n}^{\circ}$ 20, 2016, p. 89-124.

QuÉRÉ Anne-Marie, «Une conversation en breton de Plaudren », n 13 , 2004, p. 195-209.

QUÉRÉ Anne-Marie, « Remarques sur le breton parlé à Plaudren » $\mathrm{n}^{\circ} 16$, 2011, p. 111-122.

RAUDE Alan-J., « La palatalisation des consonnes vélaires en breton et britto-roman », $\mathrm{n}^{\circ}$ 5, 1991, p. 129-136.

RAUDE Alan-J., "La signalisation bilingue des noms de communes en Bretagne bretonnante $», n^{\circ} 6,1992$, p. 263-276.

RaUde Alan-J., « La fonction énonciative », n 7, 1993, p. 135-140.

RAVIER Xavier, "Des choses aux mots, des mots au discours : pour 
une utilisation maximale des données des atlas linguistiques et ethnographiques », $n^{\circ}$ 5, 1991, p. 79-97.

Rezac Milan, Jouitteau Mélanie, « Le verbe "avoir” à travers les dialectes du breton $», n^{\circ} 14,2009$, p. 115-141.

RHiour Ahmed, «Un écart balbutiant une quête de statut », $\mathrm{n}^{\circ}$ 6, 1992, p. 93-102.

Riou Yann, «À propos du breton de Lampaul-Plouarzel », $n^{\circ}$ 13, 2004, p. 211-226.

RoBerts Richard Glyn, «La Critique textuelle en rupture avec la grille épistémologique : esquisse d'une analyse des recueils de proverbes gallois du Moyen Âge », $n^{\circ} 16,2011$, p. 75-85.

RoBIN Thierry, «Flann O’Brien/Brian Ó Nualláin : portraits linguistiques d'un provocateur irlandais entre identité collective et idiosyncrasie ludique », $\mathrm{n}^{\circ} 19,2015$, p. 119-137.

Rodríguez María Fátima, «Bibliothèques captives. Politiques du livre dans les langues de l'État espagnol », $n^{\circ}$ 20, 2016, p. 15-28.

Rolland Pascal, "Deux prônes en "breton de Vannes" de la première moitié du XVIII" siècle », n 13, 2004, p. 227-252.

Ropars Jean, «Atlas linguistique des côtes françaises (littoral nord-ouest) analyse générale de l'enquête », $\mathrm{n}^{\circ}$ 2, 1986, p. 160-168.

Ropars Jean, «Atlas linguistique des côtes françaises. Île de Sein, conclusions générales de l'enquête », n 3, 1987, p. 55-63.

Ropars Jean, «Atlas linguistique des côtes françaises. Tentative d'interprétation statistique globale », $\mathrm{n}^{\circ}$ 4, 1989, p. 131-144.

Ropars Jean, «L'enfant et l'école : une expérience caractéristique. Étude d'analyse ethnotextuelle », $\mathrm{n}^{\circ}$ 5, 1991, p. 153-177.

Ropars Jean, «Contribution à l'histoire des mentalités : une méthode de recherche », $n^{\circ}$ 9, 1997, p. 137-151.

Rousseau Jean-Marie, «L'influence des transformations de l'économie bretonne sur la langue bretonne depuis le début du siècle », $\mathrm{n}^{\circ} 2,1986$, p. 126-131.

Rousseau Jean-Marie, «La monétarisation de l'économie bretonne. Une approche théorique de la diffusion de la monnaie », $n^{\circ} 3,1987$, p. 3740.

Sanogo Mamado L., Caitucoli Claude, Tsekos Nicolas, «Le PasseMuraille. Réalités langagières au Burkina Faso et en Grèce », $\mathrm{n}^{\circ}$ 10, 1996, p. 105-122.

SAULNIER Claude, " La situation sociolinguistique à Carhaix au début du siècle $», \mathrm{n}^{\circ} 7,1993$, p. 59-75.

SAUzeT Patrick, « La diglossie - conflit ou tabou ? », n 5, 1991, p. 7-40. 
SAUZET Patrick, « Paradis et parité. Ou : De la coquetterie linguistique », $n^{\circ} 10,1996$, p. 349-370.

SERIOT Patrick, «Les nations sont-elles de la compétence des linguistes ? », $\mathrm{n}^{\circ} 20,2016$, p. 135-146.

Simon Jean-François, « Recettes médicinales sur un cahier d'écolier du XVIII siècle », $\mathrm{n}^{\circ} 6,1992$, p. 79-90.

Simon Jean-François, "Pour une meilleure connaissance des techniques agricoles anciennes de Bretagne. La lexicographie au service de la technologie », $\mathrm{n}^{\circ} 17,2013$, p. 65-79.

STEPHENS Janig, « La phrase infinitive en breton », n 4, 1989, p. 189-202.

Stump Gregory T., «La morphologie bretonne et la frontière entre la flexion et la dérivation », $\mathrm{n}^{\circ} 6,1992, \mathrm{p} .185-237$.

TABouret-Keller Andrée, «Le nom des langues », $\mathrm{n}^{\circ}$ 10, 1996, p. 169176.

TABouret-KelLer Andrée, "Les "langues dialectales ou encore locales" sous le régime de Vichy », n 12, 1998, p. 89-116.

TANGUY Bernard, «Aspects de la problématique de la dialectologie comparée des domaines roman et breton (Haute et Basse-Bretagne) », $\mathrm{n}^{\circ} 1$, 1985, p. 51-58.

TANGuY Bernard, Galliou Patrick, «Armorican graffiti - prolégomènes à l'étude des graffites romains d'Armorique ", nº 4, 1989, p. 7983.

Thomas Mannaig, " "Le paysage de la grève de Penhors" : un tableau extrait du Cheval d'orgueil de Pierre-Jakez Hélias ", n 14, 2009, p. 41-56.

Thomas Mannaig, «La rhétorique "Kleiz ha Breizh”", n 17, 2013, p. 181-201.

Thomas Mannaig, «Une littérature en dépendances. La littérature de langue bretonne 2000-2010», n 18, 2014, p. 177-203.

Thomas Mannaig, Blanchard Nelly, « La carte des lieux. Connaissance et représentation de la géographie vernaculaire en breton », $\mathrm{n}^{\circ} 20,2016$, p. 161-180.

TOURNIER Maurice, « Discours polémique et schismogenèse linguistique. "Le Naven" du Père Peinard », n 10, 1996, p. 319-328.

TREmBlay Hervé, « Remarques sur le parler roman et les noms de lieu du nord-ouest de la Loire-Atlantique $», n^{\circ}$ 5, 1991, p. 57-67.

Tristram Hildegard L. C., « Orientation actuelle des études de linguistique historique, et spécialement de philologie celtique, dans les pays de langue allemande », $\mathrm{n}^{\circ}$ 4, 1989, p. 7-32.

Tristram Hildegard L. C., Hemprich Gisbert, « Esquisse de la situation 
linguistique actuelle de Fribourg-en-Brisgau (Allemagne) », $\mathrm{n}^{\circ}$ 10, 1996, p. 177-188.

Tsekos Nicolas, SAnogo Mamado L., Caitucoli Claude, «Le PasseMuraille. Réalités langagières au Burkina Faso et en Grèce », $\mathrm{n}^{\circ}$ 10, 1996, p. 105-122.

URIEN Jean-Yves, « Notes sur la démarche typologique : l'ordre des mots, le concept, le sujet, l'indéfini » (commentaires sur la communication de Steve Hewitt présentée à la journée du 11 mai 1985, cf. La Bretagne Linguistique, vol. 1, 1985, p. 223), n 2, 1986, p. 25-29.

URIEN Jean-Yves, "Le syntagme "existentiel" en breton. Définition syntaxique et sémantique $(X+$ zo / n'eus ket $+X$, “Il y a X / il n'y a pas $X ") », n^{\circ} 5,1991$, p. 179-194.

URIEN Jean-Yves, «Les Mots en "DIA-", la langue et la socialité », $\mathrm{n}^{\circ} 13$, 2004, p. 253-279.

Vecchio Sebastiano, «Y a-t-il une exception sociolinguistique italienne ?

Le cas de la Sicile », $\mathrm{n}^{\circ}$ 12, 1998, p. 337-247.

VENY Joan, «Langue historique et langue standard dans le domaine catalan », $\mathrm{n}^{\circ} 10,1996$, p. 385-394.

Vıolo Gaëlle, «Ethnographie des transmissions familiales de la langue bretonne en Basse-Bretagne », $\mathrm{n}^{\circ}$ 16, 2011, p. 7-18.

WaLter Henriette, «Le gallo hier et aujourd'hui », n 3, 1987, p. 9-35.

Wynants Armel, «Les fourons: Platt-Dütsch, Wallon, Néerlandais, Allemand, Français », n 10, 1996, p. 217-229.

WynANTs Armel, « La Belgique francophone, la Wallonie et le français », $\mathrm{n}^{\circ} 12,1998$, p. 323-335.

Wynants Armel, Deprez Kas, «Fouron : insoluble ? », n³ 3, 1987, p. 177207.

WyNANTS Bernadette, «Transformations du rapport à la norme ", $\mathrm{n}^{\circ} 10$, 1996, p. 57-67.

WynANTs Bernadette, «Usages et représentations de l'orthographe française, $n^{\circ} 12,1998$, p. 83-88. 



\section{Index des articles parus dans les numéros 1 à 20 de La Bretagne linguistique ${ }^{1}$ Classement par domaine scientifique}

Avertissement : nous avons choisi de ne faire apparaitre chaque article qu'une seule fois (domaine principal) même si certains auraient pu trouver place dans plusieurs domaines.

\section{Sociolinguistique, sociolinguistique historique}

Le Berre Annie, «Problèmes d'étude d'un français urbain de BasseBretagne : le parler de Brest ", $n^{\circ}$ 1, 1985, p. 39-46.

BRouDIC François, « La pratique du breton aujourd'hui : approche méthodologique des problèmes d'évaluation », $\mathrm{n}^{\circ} 1,1985, \mathrm{p}$. 73-80.

Benot Marcel, «Les élèves des cours moyens 1 et 2 de Milizac et la langue bretonne $», n^{\circ} 1,1985$, p. 168-177.

Le Berre Annie, « Réflexions sur la section "sociolinguistique et ethnolinguistique" du bulletin signalétique du CNRS (sciences du langage) : reflets d'un partage du monde », $\mathrm{n}^{\circ} 2,1986$, p. 70-80.

MARCELLESI Jean-Baptiste, « La sociolinguistique en France aujourd'hui : les tendances et les équipes $», \mathrm{n}^{\circ} 2,1986, \mathrm{p} .110-122$.

Rousseau Jean-Marie, "L'influence des transformations de l'économie bretonne sur la langue bretonne depuis le début du siècle », $n^{\circ} 2,1986$, p. 126-131.

George Kenneth J., « Un exemple de bilinguisme breton-anglais », $\mathrm{n}^{\circ} 2$, 1986, p. 150-158.

WALter Henriette, « Le gallo hier et aujourd'hui », n³, 1987, p. 9-35.

Rousseau Jean-Marie, « La monétarisation de l'économie bretonne. Une

1. Afin d'alléger les références, nous n'indiquons dans cet index que le numéro du volume, l'année de publication et les pages et omettons volontairement le titre de la revue ( $L a$ Bretagne linguistique), la ville et le nom de l'éditeur (Brest, Centre de recherche bretonne et celtique) pour chaque occurrence. 
approche théorique de la diffusion de la monnaie », n 3,1987 , p. 37 40.

BENot Marcel, «Attitudes à l'égard de la langue bretonne », n 3, 1987, p. 65-74.

ABRAHAM Maryvonne, « Le nom du chien en pays bretonnant », $n^{\circ} 3,1987$, p. 107-116.

BuCKLEY Thomas, «La frontière linguistique breton-gallo dans les environs de Plouha », n 3, 1987, p. 169-175.

Deprez Kas, Wynants Armel, «Fouron : insoluble ? », n 3, 1987, p. 177207.

GARDY Philippe, « Le domaine occitan depuis vingt ans : pratiques linguistiques et revendications, $\mathrm{n}^{\circ} 4,1989$, p. 99-115.

ABJEAn René, «Le bilinguisme sur une radio de service public ", $\mathrm{n}^{\circ} 4$, 1989, p. 145-151.

Crorx Alain, «Langues du peuple, langues pour le peuple. Les langages des missions bretonnes au dix-septième siècle », $\mathrm{n}^{\circ} 4,1989$, p. 155167.

SAUZET Patrick, « La diglossie - conflit ou tabou ?», n 5, 1991, p. 7-40.

GARDY Philippe, "Le personnage du Franchimand comme interlangue ", $\mathrm{n}^{\circ}$ 5, 1991, p. 41-49.

Le RouzIC Suzanne, «Une mutation linguistique en trois étapes », $\mathrm{n}^{\circ} 5$, 1991, p. 103-109.

Brasseur Patrick, «Attitudes linguistiques des Normannophones dans les Îles anglo-normandes $», n^{\circ} 5,1991$, p. 111-127.

BRoudic Fañch, «L'usage abusif du breton en 1902 : le point de vue du clergé », n 6,1992, p. 103-142.

RAUDE Alan-J., «La signalisation bilingue des noms de communes en Bretagne bretonnante », $n^{\circ}$ 6, 1992, p. 263-276.

FaVereau Francis, «Quatre générations de bretonnants », n 7, 1993, p. 31 52.

KRIER Fernande, «Le trilinguisme au Luxembourg », n 7, 1993, p. 7-20.

NiLSEN Kenneth E., « Le gaélique en Nouvelle-Écosse », nº 7, 1993, p. 7991.

BRoudic Fañch, «Réalisation d'une enquête sur la pratique du breton », $\mathrm{n}^{\circ} 7,1993$, p. 215-222.

HumPhreYs Humphrey Lloyd, «Présentation des hebdomadaires de langue galloise », $\mathrm{n}^{\circ} 8,1994$, p. 99-104.

BALIBAR Renée, "Langues internationales et minorités linguistiques 》, $\mathrm{n}^{\circ} 8,1994$, p. 115-122.

Goebl Hans, « Trois coups d'œil rapides sur la situation sociolinguistique 
dans les Alpes centrales - Grisons, Tyrol du Sud/Haut-Adige, Carinthie méridionale », $\mathrm{n}^{\circ}$ 8, 1994, p. 165-193.

ELoy Jean-Michel, « La langue est de nature sociale », n 8, 1994, p. 209222.

BERNABÉ Jean, «Un regard nouveau sur la diglossie français-créole. Esquisse d'une approche écosystémique des langues », $\mathrm{n}^{\circ}$ 9, 1997, p. 7-18.

Chetouani Lamria, «Lexicométrie et débats politiques sur l'environnement $», n^{\circ}$ 9, 1997, p. 39-64.

Manzano Francis, «Identité et frontière : linéaments d'une recherche sur le contact normano-breton », $\mathrm{n}^{\circ}$ 9, 1997, p. 105-125.

Le Dû Jean, Le Berre Yves, « Parité et disparité. Sphère publique et sphère privée de la parole », $\mathrm{n}^{\circ} 10$, Actes du colloque « Badume - Standard Norme. Le Double Jeu de la langue », 1996, p. 7-25.

BALIBAR Renée, « Colinguisme et dissonances. Les enjeux du travail des langues », $\mathrm{n}^{\circ}$ 10, Actes du colloque «Badume - Standard - Norme. Le Double Jeu de la langue », 1996, p. 27-32.

Eloy Jean-Michel, «La République et les registres langagiers », $\mathrm{n}^{\circ} 10$, Actes du colloque « Badume - Standard - Norme. Le Double Jeu de la langue », 1996, p. 33-56.

WyNANTS Bernadette, "Transformations du rapport à la norme ", $\mathrm{n}^{\circ} 10$, Actes du colloque « Badume - Standard - Norme. Le Double Jeu de la langue $», 1996$, p. 57-67.

BRoudic Fañch, «Langues parlées, langues écrites en Basse-Bretagne, 1946-1990», n 10, Actes du colloque « Badume - Standard - Norme. Le Double Jeu de la langue », 1996, p. 69-79.

HumPHREYs Humphrey Lloyd, «Réflexions sur les localismes et le supralocalisme en anglais, en gallois et en breton $», \mathrm{n}^{\circ} 10$, Actes du colloque " Badume - Standard - Norme. Le Double Jeu de la langue », 1996, p. 81-95.

NiLSEN Ken, « Le gaélique en Nouvelle-Écosse : survivance d'une langue orale au Nouveau Monde », $\mathrm{n}^{\circ} 10$, Actes du colloque "Badume Standard - Norme. Le Double Jeu de la langue », 1996, p. 97-103.

Caitucoli Claude, Sanogo Mamado L., Tsekos Nicolas, " Le PasseMuraille. Réalités langagières au Burkina Faso et en Grèce », $\mathrm{n}^{\circ}$ 10, Actes du colloque « Badume - Standard - Norme. Le Double Jeu de la langue », 1996, p. 105-122.

FaVEREAU Francis, « Normalisation d'un conte breton : à la recherche de l'impossible norme », $\mathrm{n}^{\circ} 10$, Actes du colloque « Badume - Standard Norme. Le Double Jeu de la langue », 1996, p. 123-131. 
LAROUSSI Foued, «Frontières linguistiques et pratiques langagières : Le cas tunisien », $\mathrm{n}^{\circ} 10$, Actes du colloque « Badume - Standard - Norme. Le Double Jeu de la langue », 1996, p. 133-142.

AkIN Salih, «Représentations idéologiques et réalités langagières : le cas du kurde », $\mathrm{n}^{\circ} 10$, Actes du colloque « Badume - Standard - Norme. Le Double Jeu de la langue », 1996, p. 143-151.

Clairis Christos, "La réforme linguistique en Turquie », $\mathrm{n}^{\circ} 10$, Actes du colloque « Badume - Standard - Norme. Le Double Jeu de la langue ", 1996, p. 153-157.

Jones Mari, «Le parler des jeunes : nouvelle norme pour le siècle prochain ? », n 10, Actes du colloque « Badume - Standard - Norme. Le Double Jeu de la langue », 1996, p. 159-168.

TABouret-Keller Andrée, «Le nom des langues », $\mathrm{n}^{\circ}$ 10, Actes du colloque "Badume - Standard - Norme. Le Double Jeu de la langue », 1996, p. 169-176.

Tristram Hildegard L. C., Hemprich Gisbert, « Esquisse de la situation linguistique actuelle de Fribourg-en-Brisgau (Allemagne) », $\mathrm{n}^{\circ} 10$, Actes du colloque « Badume - Standard - Norme. Le Double Jeu de la langue », 1996, p. 177-188.

Deprez Kas, « Soldats du Néerlandais », $\mathrm{n}^{\circ} 10$, Actes du colloque « Badume - Standard - Norme. Le Double Jeu de la langue », 1996, p. 189-215.

WynANTs Armel, «Les fourons : Platt-Dütsch, Wallon, Néerlandais, Allemand, Français », $n^{\circ} 10$, Actes du colloque « Badume - Standard Norme. Le Double Jeu de la langue », 1996, p. 217-229.

KRIER Fernande, "La diversité dans l'unité : les langues minoritaires », $\mathrm{n}^{\circ} 10$, Actes du colloque « Badume - Standard - Norme. Le Double Jeu de la langue », 1996, p. 231-237.

Houdebine Anne-Marie, "Imaginaire linguistique et dynamique langagière. Aspects théoriques et méthodologiques $», \mathrm{n}^{\circ} 10$, Actes du colloque « Badume - Standard - Norme. Le Double Jeu de la langue ", 1996, p. 239-255.

Hobe-Canut Cécile, «Imaginaire linguistique au Mali », $\mathrm{n}^{\circ} 10$, Actes du colloque « Badume - Standard - Norme. Le Double Jeu de la langue $», 1996$, p. 257-264.

BRUNET-HunAult Laurence, « Imaginaire linguistique et acquisition de la langue », $\mathrm{n}^{\circ}$ 10, Actes du colloque « Badume - Standard - Norme. Le Double Jeu de la langue », 1996, p. 265-272.

Gallard Philippe, «Imaginaire linguistique et français dialectal du Poitou : le sentiment identitaire chez les jeunes », $\mathrm{n}^{\circ} 10$, Actes du col- 
loque « Badume - Standard - Norme. Le Double Jeu de la langue », 1996, p. 273-279.

Bothorel-Witz Arlette, Huck Dominique, « La place des dialectes alsaciens dans un modèle variationnel : réflexions sur les notions de variétés et de normes », $\mathrm{n}^{\circ} 10$, Actes du colloque «Badume - Standard - Norme. Le Double Jeu de la langue », 1996, p. 281-297.

Garcia-Mendez Javier, "Parité et disparité parolières dans le roman hispano-américain », $\mathrm{n}^{\circ} 10$, Actes du colloque « Badume - Standard Norme. Le Double Jeu de la langue », 1996, p. 299-308.

CAHuzac Philippe, « Badumes, standards, normes. La situation en Amérique hispanique », $\mathrm{n}^{\circ} 10$, Actes du colloque « Badume - Standard Norme. Le Double Jeu de la langue », 1996, p. 309-318.

TOURnIER Maurice, « Discours polémique et schismogenèse linguistique.

Le "Naven" du Père Peinard ", $n^{\circ} 10$, Actes du colloque « Badume - Standard - Norme. Le Double Jeu de la langue », 1996, p. 319-328. GARDY Philippe, " "De l'accordéon (français ?)" Badume, Standard,

Norme dans la diglossie franco-occitane ( $\mathrm{XVI}^{\mathrm{e}}-\mathrm{XVIII}{ }^{\mathrm{e}}$ siècles). Imaginaire linguistique et dynamique langagière Aspects théoriques et méthodologiques ", $\mathrm{n}^{\circ} 10$, Actes du colloque « Badume - Standard Norme. Le Double Jeu de la langue », 1996, p. 329-347.

SAuzet Patrick, " Paradis et parité. Ou : De la coquetterie linguistique ", $\mathrm{n}^{\circ} 10$, Actes du colloque « Badume - Standard - Norme. Le Double Jeu de la langue », 1996, p. 349-370.

Geffroy Annie, " La lexicométrie : pour une approche mesurée du discours », $n^{\circ} 10$, Actes du colloque « Badume - Standard - Norme. Le Double Jeu de la langue », 1996, p. 371-383.

VENY Joan, «Langue historique et langue standard dans le domaine catalan », $\mathrm{n}^{\circ} 10$, Actes du colloque «Badume - Standard - Norme. Le Double Jeu de la langue », 1996, p. 385-394.

Blanchet Philippe, «Regard sur la dynamique ethno-sociolinguistique actuelle de la Provence, ou quand l'identité fait reculer la diglossie », $\mathrm{n}^{\circ} 11,1998$, p. 17-31.

BRoudic Fañch, « La recherche sur la pratique du breton : objet, méthodes et perspectives », $\mathrm{n}^{\circ} 11,1998$, p. 51-75.

Costaouec Denis, "Sociolinguistique et étude des changements linguistiques en synchronie », $\mathrm{n}^{\circ} 11,1998$, p. 115-119.

Eloy Jean-Michel, «Dans quel sens peut-on dire que le picard est une langue minoritaire? », $\mathrm{n}^{\circ} 11,1998$, p. 153-168.

FaLl Khadiyatoulah, «Le jeu des identités ou la plasticité du lexème "intégration" ", $\mathrm{n}^{\circ} 11,1998$, p. 169-177. 
GACHELIN Jean-Marc, «Le purisme en général, et anglo-saxon en particulier », $\mathrm{n}^{\circ} 11,1998$, p. 187-202.

German Gary, «Langue et identité : une enquête sociolinguistique menée dans huit écoles galloises portant sur les attitudes envers le gallois et l'anglais ", $\mathrm{n}^{\circ} 11,1998$, p. 203-205.

Guillou Anne, «Les femmes et le breton », n 11, 1998, p. 227-231.

Le Dû Jean, Le Berre Yves, « Faits de langues, faits de sociétés », ${ }^{\circ} 11$, 1998, p. 233-243.

Le Monze Sylvie, « Tutoiement, vouvoiement et autres formes d'adresse en français de Bretagne », $\mathrm{n}^{\circ}$ 11, 1998, p. 245-251.

L'Hourre Ronan, « Le changement de langue (en Basse Bretagne) : pour une approche centrée sur le sujet parlant », $\mathrm{n}^{\circ} 11,1998$, p. 253-271.

Megdiche Cyrille, «Approche sociologique des relations interethniques en milieu urbain », $\mathrm{n}^{\circ}$ 11, 1998, p. 273-281.

Le Dû Jean, Le Berre Yves, "Y a-t-il une exception sociolinguistique française ? ", $\mathrm{n}^{\circ} 12$, Actes du colloque "Y a-t-il une exception sociolinguistique française ?», 1998, p. 11-26.

LAFONT Robert «Langues en contact / langues en conflit ; trente ans de sociolinguistique périphérique : cinq concepts revisités ", $\mathrm{n}^{\circ} 12$, Actes du colloque "Y a-t-il une exception sociolinguistique française ? ", 1998, p. 27-38.

Marcellesi Jean-Baptiste, « Contribution à l'histoire de la sociolinguistique : origines et développement de l'école rouennaise $», n^{\circ} 12$, Actes du colloque "Y a-t-il une exception sociolinguistique française ? ", 1998, p. 39-57.

LODGE Anthony, «En quoi pourrait consister l'exception sociolinguistique française ? », $\mathrm{n}^{\circ} 12$, Actes du colloque «Y a-t-il une exception sociolinguistique française ? », 1998, p. 59-74.

Brun-Trigaud Guylaine, « La limite oc-oïl : un débat franco-allemand », $\mathrm{n}^{\circ} 12$, Actes du colloque «Y a-t-il une exception sociolinguistique française ? », 1998, p. 75-82.

WynANTs Bernadette, «Usages et représentations de l'orthographe française, $\mathrm{n}^{\circ} 12$, Actes du colloque «Y a-t-il une exception sociolinguistique française ?», 1998, p. 83-88.

TABouret-Keller Andrée, "Les "langues dialectales ou encore locales" sous le régime de Vichy », $\mathrm{n}^{\circ} 12$, Actes du colloque "Y a-t-il une exception sociolinguistique française ?», 1998, p. 89-116.

Eloy Jean-Michel, « La fille aînée du latin... est restée célibataire trop longtemps ", $\mathrm{n}^{\circ} 12$, Actes du colloque "Y a-t-il une exception sociolinguistique française ? », 1998, p. 117-140. 
LÉONARD Jean Léo, «Diasystème et diglossie périphérique: le "cas gallo-roman" ", $\mathrm{n}^{\circ} 12$, Actes du colloque « Y a-t-il une exception sociolinguistique française ?», 1998, p. 141-174.

GARDY Philippe, «Une étrange aversion? Jean Giono écrivain, "analyseur” de la situation sociolinguistique française ?, $\mathrm{n}^{\circ} 12$, Actes du colloque "Y a-t-il une exception sociolinguistique française ? », 1998, p. 175194.

Martel Philippe, "L'image de l'occitan dans l'opinion au XIX ${ }^{\mathrm{e}}$ siècle ", $\mathrm{n}^{\circ} 12$, Actes du colloque «Y a-t-il une exception sociolinguistique française ?», 1998, p. 195-217.

BRoudic Fañch, «La faute à l'abbé Grégoire ? », n 12, Actes du colloque «Y a-t-il une exception sociolinguistique française ? », 1998, p. 219228.

Mekaou Frédéric, " De la difficulté d'être soi-même entre France et Allemagne, entre modernité et tradition $», \mathrm{n}^{\circ} 12$, Actes du colloque $« \mathrm{Y}$ a-t-il une exception sociolinguistique française ?», 1998, p. 229-241.

Keryell Gaela, "La communauté des locuteurs citoyens et la communauté des locuteurs parents, nationalisme "politique" et nationalisme "culturel" ", $\mathrm{n}^{\circ} 12$, Actes du colloque «Y a-t-il une exception sociolinguistique française ?», 1998, p. 243-275.

AHLQvist Anders, «La situation sociolinguistique de l'irlandais », $\mathrm{n}^{\circ} 12$, Actes du colloque " Y a-t-il une exception sociolinguistique française? », 1998, p. 277-286.

Deprez Kas, « Pourquoi la langue officielle de la Flandre n'est-elle pas le flamand, mais le néerlandais? », $\mathrm{n}^{\circ} 12$, Actes du colloque «Y a-t-il une exception sociolinguistique française ? », 1998, p. 287-322.

WyNANTS Armel, « La Belgique francophone, la Wallonie et le français », $\mathrm{n}^{\circ} 12$, Actes du colloque $" \mathrm{Y}$ a-t-il une exception sociolinguistique française ?», 1998, p. 323-335.

Vecchio Sebastiano, «Y a-t-il une exception sociolinguistique italienne? Le cas de la Sicile », ${ }^{\circ}$ 12, Actes du colloque «Y a-t-il une exception sociolinguistique française ?», 1998, p. 337-247.

BARRÉ Ronan, "Langue et économie : quelques pistes de recherche », $\mathrm{n}^{\circ} 14,2009$, p. 195-206.

Audic Armelle, « La langue bretonne à Arradon au $\mathrm{Xx}^{\mathrm{e}}$ siècle. Essai de recherche ethno-socio-linguistique illustré par un exemple : C'hoari an Tri Roue hag ar Bassion », $\mathrm{n}^{\circ}$ 15, 2010, p. 7-27.

German Gary, «"Badume, Standard et Norme" à la lumière de l'anglais vernaculaire des Appalaches », $n^{\circ}$ 15, 2010, p. 83-107.

Broudic Jean-Yves, «Changement linguistique et processus psychiques 
inconscients liés à un trauma collectif : le cas de la Basse-Bretagne », $\mathrm{n}^{\circ} 15,2010$, p. 109-116.

Le Rol Jean-Paul, «La Passion de Pleudaniel : étude linguistique et sociolinguistique $», \mathrm{n}^{\circ} 15,2010, \mathrm{p} .117-122$.

FolLEt Jean-Philippe, « Île de Batz : le paysage sociolinguistique au début des années $1980 », \mathrm{n}^{\circ} 15,2010$, p. 146-159.

BRoudic Fañch, « Les nouveaux sondages sur la pratique du breton et celle de l'occitan en Aquitaine ", $\mathrm{n}^{\circ}$ 15, 2010, p. 185-193.

HellegouarC'H Anne, «Cymuned - aux grands maux les grands remèdes », $\mathrm{n}^{\circ} 15,2010$, p. $225-247$.

Bougthon Zoë, «La standardisation continue de la langue française : l'apport des perceptions et attitudes langagières », $\mathrm{n}^{\circ} 16,2011$, p. 37 57.

Calvez Ronan, « Les mots et les causes. Du Dictionnaire de Coëtanlem », $n^{\circ} 17,2013$, p. $15-24$.

CALvez Ronan, « Les mots et les sources », $n^{\circ}$ 17, 2013, p. 81-109.

LySAGHT Ruth, "L'image des langues minoritaires à travers les médias contemporains », $\mathrm{n}^{\circ} 17,2013$, p. 233-252.

ADAm Catherine, «Élaboration d'une recherche en sociolinguistique sur les représentations parentales et leurs influences : le cas du bilinguisme scolaire breton-français du jeune enfant $», \mathrm{n}^{\circ}$ 18, 2014, p. 33-55.

Le PIPEC Erwan, « Le breton, langue-totem ? », n 18, 2014, p. 137176.

LYSAGHT Ruth, «L'usage des langues minoritaires dans la production des émissions télévisuelles : une approche comparative des cas breton, irlandais et māori », $n^{\circ} 19,2015$, p. 55-80.

Ò HifEARNAIN Tadhg, «La pratique de l'irlandais et la minorité irlandophone $», n^{\circ} 19,2015$, p. 81-97.

LE Dû Jean, " "J'étais un vrai âne" : réflexions d'un locuteur natif sur l'évolution de la pratique du gaélique irlandais au $\mathrm{Xx}^{\mathrm{e}}$ siècle », $\mathrm{n}^{\circ} 19$, 2015, p. 99-117.

BRoudic Fañch, «Économie et langue bretonne : un rôle déterminant, deux fois? », n 19, 2015, p. 153-203.

Costa WiLson James, « Toute langue est-elle commodifiable? Quelques réflexions à partir de la situation actuelle du gaélique et de l'écossais en Écosse », nº 19, 2015, p. 205-218.

Le Squère Roseline, "Comment les usages des marques de territoire et de la symbolique régionale bretonne peuvent-ils contribuer au développement de la langue bretonne et de la culture régionale ? ", $\mathrm{n}^{\circ} 19,2015$, p. 219-237. 
AlcoufFe Alain, «Économie et langue : le cas occitan », $n^{\circ}$ 19, 2015, p. 239-259.

SERIOT Patrick, «Les nations sont-elles de la compétence des linguistes? », $\mathrm{n}^{\circ} 20,2016$, p. 135-146.

Le Berre Yves, Le Dû Jean, « Devoir et nécessité : à quoi sert le breton à ceux qui le parlent?», n² 20, 2016, p. 147-160.

Blanchard Nelly, Thomas Mannaig, " La carte des lieux. Connaissance et représentation de la géographie vernaculaire en breton », $\mathrm{n}^{\circ} 20,2016$, p. 161-180.

\section{Dialectologie et géographie linguistique}

TANGUY Bernard, "Aspects de la problématique de la dialectologie comparée des domaines roman et breton (Haute et Basse-Bretagne) », $\mathrm{n}^{\circ} 1,1985$, p. 51-58.

FALC'HUN François, " La structure linguistique du domaine bretonnant », $\mathrm{n}^{\circ} 1,1985$, p. 59-71.

Plourin Jean-Yves, "L'accentuation en Haute-Cornouaille et en BasVannetais $», n^{\circ} 1,1985$, p. 103-115.

George Kenneth J., " Le cornique : un cinquième dialecte du breton? 》, $\mathrm{n}^{\circ} 1,1985$, p. 117-124.

FLATRÈs Pierre, « Lang Kouter (lankouta) - L'argot des tailleurs d'Elliant (Finistère) $», n^{\circ} 1,1985$, p. 137-141.

LE Dû Jean, «Dialectologie et géographie linguistique de la BasseBretagne $», n^{\circ} 1,1985$, p. 145-167.

Evenou Yvon, « Oppositions de longueur vocalique et formes canoniques dans le breton de Lanvenegen (canton du Faouët) », $n^{\circ}$ 1, 1985, p. 179189.

Chauveau Jean-Paul, «Quelques emprunts du gallo au breton», $\mathrm{n}^{\circ} 1$, 1985, p. 191-204.

GuYONVARC' H Christian-Joseph, « Dialectes et moyen-breton », $\mathrm{n}^{\circ}$ 1, 1985, p. 133- 135.

Horiot Brigitte, « Le travail de dialectologie dans le domaine de l'ALO », $\mathrm{n}^{\circ} 2,1986$, p. $98-106$.

Ropars Jean, «Atlas linguistique des côtes françaises (littoral nord-ouest), analyse générale de l'enquête », $\mathrm{n}^{\circ}$ 2, 1986, p. 160-168.

Ropars Jean, «Atlas linguistique des côtes françaises. Île de Sein, conclusions générales de l'enquête », n 3, 1987, p. 55-63.

ROPARs Jean, «Atlas linguistique des côtes françaises. Tentative d'interprétation statistique globale », $\mathrm{n}^{\circ}$ 4, 1989, p. 131-144. 
RAUDE Alan-J., « La palatalisation des consonnes vélaires en breton et britto-roman », $\mathrm{n}^{\circ}$ 5, 1991, p. 129-136.

LE Dû Jean, «Pour un Atlas linguistique collectif de la langue bretonne », $\mathrm{n}^{\circ}$ 7, 1993, p. 21- 30.

Le Besco Patrick, «Le breton de Belle-Île-en-Mer, quelques caractéristiques », $\mathrm{n}^{\circ}$ 7, 1993, p. 141-149.

German Gary, «Une méthode dialectométrique (assistée par ordinateur) pour l'analyse des atlas linguistiques $», \mathrm{n}^{\circ} 7,1993$, p. 177-213.

CADIOU Hervé, «Y a-t-il eu une influence de la langue écrite sur le parler du Léon? », n 7, 1993, p. 223-226.

PlonéIs Jean-Marie, «Toponymie : contribution à la dialectologie bretonne », n 8, 1994, p. 91-97.

Le Besco Patrick, «L'argot des maçons de la Forêt-Fouesnant ", $\mathrm{n}^{\circ} 8$, 1994, p. 105-106.

HugHes Arthur John, «Les mots qui désignent le cheval dans les langues gaéliques du point de vue de la géographie linguistique », $\mathrm{n}^{\circ} 8,1994$, p. 223-259.

Bernier Gildas, «Phonologie du breton de Quiberon », n 8, 1994, p. 261271.

Brun-Trigaud Guylaine, «À propos des atlas linguistiques régionaux. Problèmes de comparabilité », $\mathrm{n}^{\circ} 11,1998$, p. 33-49.

DAlBera Jean-Philippe, « Espace et variation linguistique : description et modélisation. Les bases de données THESOC et ALCANOM », $n^{\circ} 11$, 1998, p. 121-134.

Dalbera-Stefanaggi Marie-José, «La base de données dialectales : un instrument de sauvegarde et de recherche. L'exemple corse $», \mathrm{n}^{\circ} 11$, 1998, p. 135-152.

LE Dû Jean, « Introduction : La dialectologie et la géolinguistique bougent encore! », $n^{\circ} 13$, « Dialectologie et Géolinguistique », 2004, p. 5-11.

Blanchard Nelly, «L'utilisation pédagogique des textes du concours $\mathrm{Ar}$ Falz », n 13, « Dialectologie et Géolinguistique », 2004, p. 13-29.

BRoudic Fañch, «La perception de la variation diatopique au fil du temps », $\mathrm{n}^{\circ} 13$, « Dialectologie et Géolinguistique », 2004, p. 31-52.

BRUN-TRIGAUd Guylaine, "Le breton : un éclairage sur l'histoire des parlers gallo-romans ? », n 13, " Dialectologie et Géolinguistique », 2004, p. 53-71.

FAGON Christian, « Changement du/z/ en /h/ en Léon : continuité du brittonique au breton moderne et regard sociolinguistique des locuteurs sur ce phénomène », $\mathrm{n}^{\circ} 13$, « Dialectologie et Géolinguistique », 2004, p. $73-83$. 
FAVEREAU Francis, « Déictiques spatio-temporels en breton central », $\mathrm{n}^{\circ} 13$, « Dialectologie et Géolinguistique », 2004, p. 85-103.

Giraudon Daniel, «Ornithonymes et breton populaire. Des cris, des couleurs, des mœurs et des genres », $n^{\circ} 13$, « Dialectologie et Géolinguistique », 2004, p. 105-127.

Goyat Gilles, " La deuxième personne dans le parler breton de Plozévet », $\mathrm{n}^{\circ} 13$, « Dialectologie et Géolinguistique », 2004, p. 129-138.

LEDUNOIS Jean-Pierre, «Grammaire et dialectologie », $\mathrm{n}^{\circ} 13$, « Dialectologie et Géolinguistique », 2004, p. 139-156.

Le PIPEC Erwan, "Lecture critique du Nouvel Atlas Linguistique de la Basse-Bretagne », $\mathrm{n}^{\circ}$ 13, « Dialectologie et Géolinguistique », 2004, p. $157-175$.

Plourin Jean-Yves, « La grammaire bretonne à l'épreuve des dialectes », $n^{\circ} 13$, « Dialectologie et Géolinguistique », 2004, p. 177-193.

QuÉRÉ Anne-Marie, «Une conversation en breton de Plaudren », n 13, « Dialectologie et Géolinguistique », 2004, p. 195-209.

Riou Yann, « À propos du breton de Lampaul-Plouarzel », $n^{\circ}$ 13, « Dialectologie et Géolinguistique », 2004, p. 211-226.

Rolland Pascal, "Deux prônes en "breton de Vannes" de la première moitié du XVIII siècle », $\mathrm{n}^{\circ} 13$, «Dialectologie et Géolinguistique », 2004, p. 227-252.

Urien Jean-Yves, "Les Mots en "DIA-", la langue et la socialité », $\mathrm{n}^{\circ}$ 13, « Dialectologie et Géolinguistique », 2004, p. 253-279.

CAnobBio Sabina, «L'Atlas Linguistique comme outil de recherche ? À propos de quelques expériences italiennes », $\mathrm{n}^{\circ} 13$, «Dialectologie et Géolinguistique», 2004, p. 281-312.

GACHELIN Jean-Marc, «Un aperçu du lexique de l'anglais dialectal », $\mathrm{n}^{\circ} 13$, « Dialectologie et Géolinguistique », 2004, p. 313-330.

García-Mouton Pilar, « Sur la dialectologie espagnole », n 13, « Dialectologie et Géolinguistique », 2004, p. 331-340.

GERMAN Gary, « Analyse diachronique et variationniste de la désinence du pluriel -EN en anglais standard et non standard », $n^{\circ} 13$, « Dialectologie et Géolinguistique », 2004, p. 105-127.

Goebl Hans, "Brève présentation de l'Atlas linguistique ladin (ALD $1^{\text {ère et }} 2^{\mathrm{e}}$ partie) », $\mathrm{n}^{\circ} 13$, « Dialectologie et Géolinguistique », 2004, p. 375-381.

Kretzschmar William A., «Vingt années de l'American Linguistic Atlas Project », $\mathrm{n}^{\circ}$ 13, « Dialectologie et Géolinguistique », 2004, p. 383400. 
LE Dû Jean, «Thésaurus des noms de poissons d'animaux marins et du bord de mer des côtes de Basse-Bretagne », $n^{\circ}$ 14, 2009, p. 69-79.

LE BRIs Daniel, « Les études linguistiques d'Edward Lhuyd en Bretagne en $1701 », n^{\circ} 14,2009$, p. 175-193.

Cheveau Loic, « Le breton de Ploemeur d'après l'ALBB de P. Le Roux : lecture critique $», n^{\circ} 15,2010$, p. 29-42.

Le Dû Jean, « Un atlas linguistique du créole des Petites Antilles (ALPA) » $\mathrm{n}^{\circ} 16,2011$, p. $59-74$.

QUÉRÉ Anne-Marie, « Remarques sur le breton parlé à Plaudren » $\mathrm{n}^{\circ} 16$, 2011, p. 111-122.

Le BrIs Daniel, «Entre Penzé et Rivière de Morlaix : termes nautiques bretons relevés par Coëtanlem », n 17, 2013, p. 111-123.

Dell'aquila Vittorio, Iannaccaro Gabriele, "Quelques considérations sur la cartographie des données linguistiques », $\mathrm{n}^{\circ} 17,2013$, p. 253-286.

Brun-Trigaud Guylaine, "Le Thesaurus Occitan, une base de données multimédiale dédiée aux dialectes occitans », $\mathrm{n}^{\circ} 18,2014$, p. 57-72.

Le Bris Daniel, CARPITElli Elisabetta, « Concordances linguistiques entre aires celtique et romane à partir des données des atlas multilingues ", $\mathrm{n}^{\circ} 18,2014$, p. $73-85$.

Desseigne Adrien, Kersulec Pierre-Yves, « Les enquêtes dialectologiques de la Société d'Ethnolinguistique Bretonne : éléments de présentation du Questionnaire grammatical $1500 », \mathrm{n}^{\circ} 18,2014$, p. 87-109.

Chatelier Antoine, «La particule verbale "en" dans le standard de Vannes », n 19,2015 , p. 281-295.

Le PIPEC Erwan, «La palatalisation vannetaise », n 19, 2015, p. 297-327. Crahé Maxime-Morvan, «Les occurrences de [ç] dans le parler de Languidic (breton haut-vannetais) », $\mathrm{n}^{\circ} 20,2016$, p. 125-133.

\section{Linguistique, linguistique historique, phonologie}

FLEURIOT Léon, «Évolutions anciennes et récentes en breton », n 1, 1985, p. 87-97.

CADIOU Hervé, « Les colloques français-breton à la croisée des rapports du français et du breton », $\mathrm{n}^{\circ} 1,1985$, p. 125-131.

HewitT Stephen, «Quelques ressemblances structurales entre le breton et

l'arabe : conséquence d'une typologie ordinale commune ?», $\mathrm{n}^{\circ} 1$, 1985, p. 223-262.

Le Duc Gwenaël, «La Vie de Geneviève de Brabant : la langue comme écran et révélateur », $\mathrm{n}^{\circ} 1,1985$, p. 263-275.

URIEN Jean-Yves, « Notes sur la démarche typologique : l'ordre des mots, 
le concept, le sujet, l'indéfini » (commentaires sur la communication de Steve Hewitt présentée à la journée du 11 mai 1985, cf. La Bretagne Linguistique, vol. 1, 1985, p. 223)», n² 2, 1986, p. 25-29.

PILCH Herbert, «L'accentuation de la langue bretonne », $\mathrm{n}^{\circ} 2$ 2, 1986, p. 4368.

Plourin Jean-Yves, CADIC Mireille, «Aspects linguistiques de l'émigration langonnetaise vers l'Amérique », n² 2, 1986, p. 82-86.

HewitT Steve, « Le progressif en breton à la lumière du progressif anglais », n² 2, 1986, p. 133-148.

LAMBERT Pierre-Yves, « Nouvelles orientations de la recherche dans l'étude des gloses celtiques (en particulier brittoniques) », $\mathrm{n}^{\circ} 3,1987$, p. 99105.

GERMAN Gary, «L'histoire phonologique du déterminant défini et indéfini à Saint-Yvi en Cornouaille selon les observations faites par De Jubainville à Fouesnant en $1874 », n^{\circ} 3,1987$, p. 157-168.

Tristram Hildegard C., "Orientation actuelle des études de linguistique historique, et spécialement de philologie celtique, dans les pays de langue allemande $», n^{\circ} 4,1989$, p. 7-32.

OMNÈs Robert, « Structures et modèles syllabiques », $\mathrm{n}^{\circ}$ 4, 1989, p. 53-78.

Evenou Yvon, «La proposition dite relative dans le breton de Lanvénégen », n 4, 1989, p. 121-129.

George Kenneth J., "Quelques réflexions sur l'ordre des mots dans la pièce en moyen breton Buhez Santez Nonn », n 4, 1989, p. 175-187.

StePHens Janig, « La phrase infinitive en breton », $\mathrm{n}^{\circ}$ 4, 1989, p. 189-202.

HewitT Steve, "Un cadre descriptif pour la syntaxe du verbe breton », $\mathrm{n}^{\circ} 4,1989$, p. 203-211.

URIEN Jean-Yves, «Le syntagme "existentiel" en breton. Définition syntaxique et sémantique $(X+$ zo / n'eus ket $+X$, “Il y a X / il n'y a pas X")», n 5, 1991, p. 179-194.

BANKs David, «Transitivité systémique et analyse du texte », n 6, 1992, p. 45-52.

Pilch Herbert, «L'intonation de la langue bretonne », n 6, 1992, p. 175182.

STUMP Gregory T., « La morphologie bretonne et la frontière entre la flexion et la dérivation $», \mathrm{n}^{\circ} 6,1992$, p. 185-237.

Guyonvarc'H Christian-Joseph, «La langue gauloise dans le De Bello gallico », n 6, 1992, p. 239-251.

BÉCHEREL Danielle, «Restrictions sémantiques dans la transformation adjectif/substantif $», n^{\circ} 6,1992$, p. 255-261.

NOAILLY Michèle, «Autour du défini cataphorique », nº 7, 1993, p. 93-101. 
RAUDE Alan-J., « La fonction énonciative », n 7, 1993, p. 135-140.

Chauveau Jean-Paul, «Le Französisches Etymologisches Wörterbuch de

Walter von Wartburg et son intérêt pour des celtisants », $n^{\circ}$ 9, 1997, p. 19-37.

Goyat Gilles, « Prosodie et prosodie musicale », n 9, 1997, p. 65-76.

PlouRIN Jean-Yves, «La phrase bretonne comprenant le verbe ÊTRE au présent de l'indicatif. Conflits de topicalisation ", n 11, 1998, p. 283300.

LE PIPEC Erwan, "La phrase négative en breton : de la phonologie à la syntaxe $», n^{\circ} 14,2009$, p. 57-67.

JouitTEAu Mélanie, ReZAC Milan, « Le verbe “avoir” à travers les dialectes du breton », $n^{\circ} 14,2009$, p. 115-141.

Plourin Jean-Yves, "Continu et discontinu dans le groupe nominal », $\mathrm{n}^{\circ} 14,2009$, p. 143-174.

JøRGENSEN Anders Richardt, «On Breton "meliner" (miller) and other agent noun derivatives with Latin "ator" ", n 14, 2009, p. 207-226.

Favereau Francis, «Le je(u) de chaises musicales du breton », $n^{\circ}$ 14, 2009, p. 227-239.

IRSLINGER Britta, «Les dérivés gallois, cornique en -yn / -en, breton en -enn et irlandais en -ne : fonction et sémantique $», n^{\circ} 15,2010$, p. $43-$ 81.

Costaouec Denis, «Contraintes et libertés en phonologie : neutralisations et faits d'assimilation en breton », $\mathrm{n}^{\circ} 15,2010, \mathrm{p} .123-145$.

Le RUYET Jean-Claude, «Effet Buben, liaison et modèles orthographiques bretons " $\mathrm{n}^{\circ} 16,2011$, p. 97-109.

JøRGENSEN Anders Richardt, « On the sources and transmission of the Early Vannetais noels », $\mathrm{n}^{\circ} 17,2013$, p. 203-231.

Louis François et MiLıćEvić Jasmina, «Combien d'acceptions le mot keuz "regret" a-t-il ? (Lexémisation du vocable keuz) », n 18, 2014, p. 205-226.

JouitTeau Mélanie, «Pronoms impersonnels dans le breton vannetais de Loeiz Herrieu. Syntaxe, sémantique et usages en concurrence avec le passif », $\mathrm{n}^{\circ} 19,2015$, p. 261-280.

\section{Orthographe, lexicologie, toponymie, anthroponymie}

HumPhreys Humphrey Lloyd, « Projet d'un dictionnaire de la prononciation des toponymes bretons (DPTB) », $\mathrm{n}^{\circ} 2,1986$, p. 9-23.

PlonÉIs Jean-Marie, «Toponymie : formes orales et écrites. Évolutions phonétiques », $\mathrm{n}^{\circ} 2,1986$, p. 31-35. 
FALC'HUN François, «Introduction à une étude des noms de lieux celtiques de la Mayenne, d'après le Dictionnaire topographique du département par Léon Maître (1878)», n² 2, 1986, p. 37-39.

HewitT Steve, « Réflexions et propositions sur l'orthographe du breton », $\mathrm{n}^{\circ} 3,1987$, p. 41-54.

CAHUzac Philippe, "Approche théorique et pratique de quelques problèmes posés à la recherche lexicographique d'aujourd'hui », $\mathrm{n}^{\circ} 3$, 1987, p. 77-93.

Flatrès Pierre, «La toponymie orale comme témoignage d'une langue éteinte », $\mathrm{n}^{\circ}$ 3, 1987, p. 95-98.

CADIou Hervé, « À propos d'orthographe », n 3, 1987, p. 117-124.

PINOT Jean-Pierre, « Noms donnés par les pêcheurs aux fonds sous-marins sur le plateau continental sud-armoricain $», n^{\circ} 4,1989$, p. 85-95.

Tremblay Hervé, « Remarques sur le parler roman et les noms de lieu du nord-ouest de la Loire-Atlantique », $n^{\circ}$ 5, 1991, p. 57-67.

MaAs-Chauveau Claudia «Présentation des recherches en onomastique du Patronymia romanica », $\mathrm{n}^{\circ}$ 5, 1991, p. 99-102.

Lecoce Jean-Marc, « Les mots d'origine bretonne dans l'argot français », $\mathrm{n}^{\circ} 7,1993$, p. 227-238.

Plourin Jean-Yves, « De quelques mots bretons anciens », $\mathrm{n}^{\circ}$ 9, 1997, p. 127-135.

KeRsulec Pierre-Yves, «Les noms en -erezh à référence collective : esquisse de classement $», \mathrm{n}^{\circ} 15,2010$, p. 249-274.

\section{Littérature}

PIRIOU Yann-Ber, «Notes de lecture : Les amours d'un vieillard », $\mathrm{n}^{\circ} 2$, 1986, p. 88-97.

Le Roc'h-Morgère Louis, « Sur Charlemagne et les douze pairs de France, tragédie bretonne du XVII ${ }^{e}$ siècle », $\mathrm{n}^{\circ} 4$, 1989, p. 117-119.

Bourel Claude, «Présentation d'un conte de Haute-Bretagne : Le cheval noir et le vagabond (approche linguistique et symbolique), $\mathrm{n}^{\circ} 4,1989$, p. 169-174.

PLÖTNER Bärbel, «La correspondance entre Hersart de La Villemarqué et un savant allemand, Jacob Grimm », $n^{\circ}$ 6, 1992, p. 7-44.

BALCOU Jean, «Ernest Renan et la langue bretonne », n 6, 1992, p. 69-78.

Le Berre Yves, "Un "Supplément" au Livr el labourer de Joachim Guillôme, n 6, 1992, p. 159-174.

Le BerRe Yves, «L'écriture du breton dans l'histoire. Essai de synthèse ", $\mathrm{n}^{\circ}$ 7, 1993, p. 153-176. 
Le Rouzic Suzanne, «Un écrivain de langue bretonne l'Abbé Pierre Noury : 1743-1804», n 8, 1994, p. 107-111.

Le Berre Yves, Le Dû Jean, « L'élaboration d'une banque de données textuelles du breton », n 9, 1997, p. 99-104.

Le Berre Yves, "À propos du Stabat Mater breton de Tanguy Guéguen (1622) : le "moyen-breton" existe-t-il ?», n 14, 2009, p. 13-24.

CALVEz Ronan, « La métaphore mondaine. Kerenveyer et les littératures du breton $», n^{\circ} 14,2009$, p. 25-40.

Thomas Mannaig, " "Le paysage de la grève de Penhors" : un tableau extrait du Cheval d'orgueil de Pierre-Jakez Hélias », $\mathrm{n}^{\circ}$ 14, 2009, p. 41-56.

Blanchard Nelly, "Le manuscrit autobiographique d'Hervé Burel : le peuple dit par lui-même? ", $\mathrm{n}^{\circ}$ 14, 2009, p. 93-105.

Mouton Jacques-Yves, «Le mythe de Tir Na N-og chez les premiers Liammistes $», \mathrm{n}^{\circ} 14,2009$, p. 107-113.

CAssard Jean-Christophe, "Le breton dans la bd franco-belge », $\mathrm{n}^{\circ} 15$, 2010, p. 195-223.

Choplin Cédric, «Feiz ha Breiz (1865-1884) ou la genèse d'une langue journalistique $», \mathrm{n}^{\circ} 16,2011, \mathrm{p} .19-35$.

ROBERTs Richard Glyn, « La Critique textuelle en rupture avec la grille épistémologique : esquisse d'une analyse des recueils de proverbes gallois du Moyen Âge », n 16, 2011, p. 75-85.

Le Berre Yves, "La force et l'élégance. Les litotes dans la Passion bretonne de $1530 », n^{\circ} 16,2011$, p. 123-149.

Le Berre Yves, «Présentation de la journée du 11 février 2011 », n 17, 2013, p. 125-126.

CALVEz Ronan, «Amours cachées: la nouvelle rhétorique mondaine bretonne $», n^{\circ} 17,2013$, p. 127-139.

Le BerRe Yves, « Rhétorique des gwerziou », n 17, 2013, p. 141-160.

BlanCHARD Nelly, «Les doublets synonymiques chez Hervé Burel (1905) ou comment casser l'entre-soi », $\mathrm{n}^{\circ}$ 17, 2013, p. 161-180.

Thomas Mannaig, « La rhétorique "Kleiz Breizh" ", n 17, 2013, p. 181201.

Blanchard Nelly, «Julien Godest, paysan autobiographe sous l'aile de Taldir-Jaffrennou », $\mathrm{n}^{\circ}$ 18, 2014, p. 7-31.

Thomas Mannaig, «Une littérature en dépendances. La littérature de langue bretonne 2000-2010», n 18, 2014, p. 177-203.

GLON Thierry, «Esthétique du régionalisme », nº 19, 2015, p. 43-54.

RoBIN Thierry, «Flann O’Brien/Brian Ó Nualláin : portraits linguistiques 
d'un provocateur irlandais entre identité collective et idiosyncrasie ludique $», n^{\circ} 19,2015$, p. 119-137.

Dochy Amélie, «Pleasing, Emotionally Touching and Convincing: Erskine Nicol's Painting of Ireland and the Irish in the Mid-Nineteenth Century », n 19, 2015, p. 139-152.

CARRÉ Daniel, "Courrier de guerre de Loeiz Herrieu à son épouse.

Considérations stylistiques et style épistolaire », $\mathrm{n}^{\circ} 19,2015$, p. 329342.

Heulin Antony, «Loeiz Herrieu, de la langue des carnets à la langue littéraire $», n^{\circ} 19,2015$, p. 343-361.

Broudic Fañch, «Actualité d'Emgleo Breiz? », n 20, 2016, p. 183-190.

Rodríguez María Fátima, "Bibliothèques captives. Politiques du livre dans les langues de l'État espagnol », $\mathrm{n}^{\circ}$ 20, 2016, p. 15-28.

Fañch Postic et Nelly Blanchard, «Almanak Breiz-Izel (1872) : l'essai manqué d'un almanach républicain en breton », $\mathrm{n}^{\circ} 20,2016$, p. 89-124.

\section{Histoire, archéologie}

GuIOMAR Jean-Yves, « Les historiens et la langue bretonne au XIX ${ }^{\mathrm{e}}$ siècle », $\mathrm{n}^{\circ} 1,1985$, p. 99-102.

GALLIOU Patrick, «L'Armorique romaine : assimilation ou résistance ? », $\mathrm{n}^{\circ} 1,1985$, p. 205-221.

GoulETQuer Pierre, «Des pierres et des mots; quelques aspects des convergences entre archéologie et linguistique $», n^{\circ} 3,1987, \mathrm{p} .145-155$.

GoulEtQuer Pierre, «Archéologie intégrée. La recherche archéologique et ses facteurs déterminants : l'exemple du Finistère ", $n^{\circ} 4,1989$, p. 33-51.

Galliou Patrick, TanguY Bernard, «Armorican graffiti : prolégomènes à l'étude des graffites romains d'Armorique », n 4, 1989, p. 79-83.

LAMBERT Pierre-Yves, " La situation linguistique de la Bretagne au Haut Moyen Âge », n 5, 1991, p. 139-151.

GouletQuer Pierre, «Opacité sémantique et discontinuité de l'information archéologique », $n^{\circ} 6,1992$, p. 253-254.

Gouletquer Pierre, «Barnenez-ar-Zant et ses symboles », nº 7, 1993, p. 103-133.

Guiomar Jean-Yves, «L'introduction en France des idées sur l'origine celtique de la littérature française par l'Abbé Gervais de La Rue », $n^{\circ} 8,1994$, p. 7-89.

Flatrès Pierre, «La notion de nation dans les Îles Britanniques », $\mathrm{n}^{\circ} 8$, 1994, p. 195-207. 
IsAAC Luc, «Aspects de la question linguistique en Belgique », $\mathrm{n}^{\circ}$ 9, 1997, p. 83-98.

RopARs Jean, «Contribution à l'histoire des mentalités : une méthode de recherche », $\mathrm{n}^{\circ}$ 9, 1997, p. 137-151.

BALIBAR Renée, «La langue romane-française », n 11, 1998, p. 7-15.

Calvez Ronan, «Vie et mort du paysanisme breton : Feiz ha Breiz (18651875) $\gg, n^{\circ} 11,1998$, p. 77-96.

CaLvez Ronan, " "Les Bretons parlent aux Bretons". Radio-Quimerc'h :

les débuts de la radio en breton », $\mathrm{n}^{\circ} 11,1998$, p. 97-113.

FAUQUET Eric, « La question de la génialité de la langue. Transfert des idées de Herder en France », n 11, 1998, p. 179-186.

GouletQuer Pierre, «Cadastre napoléonien, archéologie et territoires parlés », n 11, 1998, p. 207-212.

GouletQuer Pierre, "Géographie linguistique et archéo-géographie ;

plaidoyer pour des démarches interdisciplinaires », $\mathrm{n}^{\circ} 11,1998$, p. 213-225.

Guillorel Éva, «Le Barzaz Bro-Leon, ou la tentative d'un nouveau Barzaz-Breiz: premières approches d'un fonds inédit de près de 1000 chansons en breton $», n^{\circ} 14,2009$, p. 81-92.

CARney Sébastien, «Célestin Lainé et le breton : la langue pour le combat », $n^{\circ} 16,2011$, p. 151-197.

Coumert Magali, «Existe-t-il une "ancienne loi des Bretons d'Armorique" ? Identités ethniques et tradition manuscrite au haut Moyen Âge », $\mathrm{n}^{\circ} 18,2014$, p. 227-264.

Lespoux Yan, «Vidas. Création d'un dictionnaire biographique des acteurs de la renaissance d'oc en ligne : nécessité et contraintes », $\mathrm{n}^{\circ} 20,2016$, p. 191-198.

\section{Ethnologie}

FolLet Jean-Philippe, « Essai de recherche ethnotextuelle à l'Île de Batz (Finistère) $», \mathrm{n}^{\circ} 1,1985$, p. 81-83.

LaURent Donatien, « La troménie de Locronan. La fête de Lughnasa et le calendrier celtique $», n^{\circ} 3,1987$, p. 127-143.

Le GuIRRIEC Patrick, « La nomenclature des termes de référence en Bretagne $», n^{\circ} 5,1991$, p. 51-56.

PlonÉIs Jean-Marie, « Le paysan et ses animaux. Quelques aspects linguistiques $», n^{\circ} 5,1991$, p. 69-76.

RAVIER Xavier, " Des choses aux mots, des mots au discours : pour une 
utilisation maximale des données des atlas linguistiques et ethnographiques », $\mathrm{n}^{\circ} 5,1991, \mathrm{p} .79-97$.

Ropars Jean, « L'enfant et l'école : une expérience caractéristique. Étude d'analyse ethnotextuelle », $\mathrm{n}^{\circ}$ 5, 1991, p. 153-177.

Le Berre Annie, «Bretagne : terre incognita? À propos d'une enquête sur la connaissance de la Bretagne dans une classe de première brestoise, année scolaire 1987-1988 », n 5, 1991, p. 197-218.

Simon Jean-François, «Recettes médicinales sur un cahier d'écolier du XVIII ${ }^{e}$ siècle », $\mathrm{n}^{\circ} 6,1992$, p. 79-90.

Flatrès Pierre, «Abandon de langue et transmission de traditions : à propos de quelques rencontres avec le paganisme celtique $" \mathrm{n}^{\circ} 7$, 1993, p. 53-58.

LAMPLE Bernard, "Les pêcheurs kerhorres : une communauté originale dans la rade de Brest », $\mathrm{n}^{\circ}$ 8, 1994, p. 123-134.

Kalyguine Victor, «La poétique irlandaise archaïque du point de vue mythologique. Domestication de l'espace », $\mathrm{n}^{\circ} 8$, 1994, p. 135-143.

Evenou Yvon, «Breton et culture bretonne dans l'éducation nationale », $\mathrm{n}^{\circ} 8,1994$, p. 145-154.

LECOQ Jean-Marc, « Les argots bretons, langages secrets professionnels en Basse-Bretagne », n 8, 1994, p. 155- 162.

GiRAudon Daniel, «Les blasons populaires en Bretagne », $\mathrm{n}^{\circ}$ 15, 2010, p. 161-168.

Postic Fañch, «Le fonds La Villemarqué : une source importante pour l'histoire de l'ethnographie et des études celtiques ", $\mathrm{n}^{\circ} 15,2010$, p. 169-183.

Vıolo Gaëlle, «Ethnographie des transmissions familiales de la langue bretonne en Basse-Bretagne », n 16, 2011, p. 7-18.

Gоунт Gilles, « La langue bretonne dans la Mission de folklore musical de Basse-Bretagne de 1939, n 16, 2011, p. 87-96.

Postic Fañch, "Les dictionnaires bretons, une source pour l'ethnographie : l'article "Eghinat" chez Coëtanlem et Le Pelletier ", $\mathrm{n}^{\circ} 17$, 2013, p. 25-64.

Simon Jean-François, «Pour une meilleure connaissance des techniques agricoles anciennes de Bretagne. La lexicographie au service de la technologie $», n^{\circ} 17,2013$, p. 65-79.

LE GaLL Laurent, « La Bretagne, une illusio qui fonctionne », $\mathrm{n}^{\circ}$ 18, 2014, p. 11-136.

GaLL Laurent, «Kant plantenn, kant anv. Inflorescence linguistique en Basse-Bretagne », $\mathrm{n}^{\circ}$ 19, 2015, p. 7-25. 
PoLi Muriel, «Quand la polysémie se généralise : le labre, le roitelet et l'euprocte se font "vieux". Les désignations relatives à la nature en langue corse $», n^{\circ} 19,2015$, p. 27-42.

Philippe Tanguy, «Gleb - Analyse croisée des registres sportifs et langagiers dans le cas du gouren/lutte bretonne $», n^{\circ} 20,2016$, p. 29-43.

Boudillet Estelle, " "Des étrangers et des gens du dehors". Ou quand les Johnnies ne s'appelaient pas Petit Jean », n² 20, 2016, p. 45-88. 